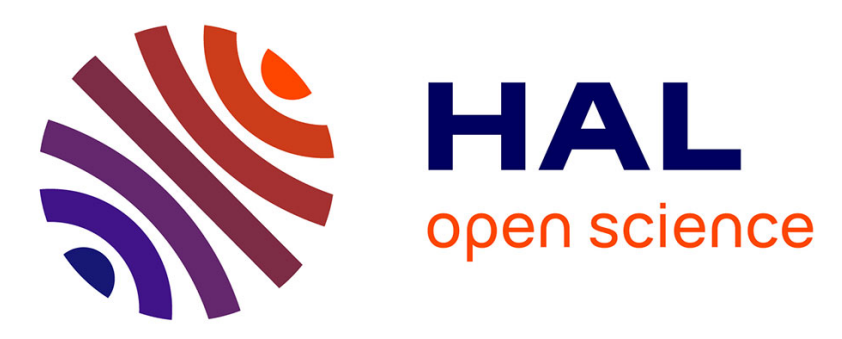

\title{
Insight into the mechanisms of enhanced retinal transduction by the engineered AAV2 capsid variant $-7 \mathrm{~m} 8$
}

Hanen Khabou, Mélissa Desrosiers, Céline Winckler, Stéphane Fouquet, Gwenaëlle Auregan, Alexis-Pierre Bemelmans, José-Alain Sahel, Deniz Dalkara

\section{To cite this version:}

Hanen Khabou, Mélissa Desrosiers, Céline Winckler, Stéphane Fouquet, Gwenaëlle Auregan, et al.. Insight into the mechanisms of enhanced retinal transduction by the engineered AAV2 capsid variant -7m8. Biotechnology and Bioengineering, 2016, 113 (12), pp.2712-2724 10.1002/bit.26031 . hal01346351

\section{HAL Id: hal-01346351 \\ https://hal.sorbonne-universite.fr/hal-01346351}

Submitted on 18 Jul 2016

HAL is a multi-disciplinary open access archive for the deposit and dissemination of scientific research documents, whether they are published or not. The documents may come from teaching and research institutions in France or abroad, or from public or private research centers.
L'archive ouverte pluridisciplinaire HAL, est destinée au dépôt et à la diffusion de documents scientifiques de niveau recherche, publiés ou non, émanant des établissements d'enseignement et de recherche français ou étrangers, des laboratoires publics ou privés. 
Title:

Insight into the mechanisms of enhanced retinal transduction by the engineered AAV2 capsid variant $-7 \mathrm{~m} 8$

Running title: Mechanisms of enhanced transduction by AAV2-7m8

Authors: Hanen Khabou ${ }^{1}$, Mélissa Desrosiers ${ }^{1}$, Céline Winckler ${ }^{1}$, Stéphane Fouquet ${ }^{1}$, Gwenaëlle Auregan $^{3,4}$, Alexis-Pierre Bemelmans ${ }^{3,4}$, José-Alain Sahel ${ }^{1,2}$, Deniz Dalkara ${ }^{1 \#}$

\begin{abstract}
Affiliations:
${ }^{1}$ Sorbonne Universités, UPMC Univ Paris 06, INSERM, CNRS, Institut de la Vision, 17 rue Moreau, 75012 Paris, France. ${ }^{2}$ CHNO des Quinze-Vingts, DHU Sight Restore, INSERM-DHOS CIC, 28 rue de Charenton, 75012 Paris, France. ${ }^{3}$ Commissariat à l'Energie Atomique et aux Energies Alternatives (CEA), Département des Sciences du Vivant (DSV), Institut d'Imagerie Biomédicale (I2BM), Molecular Imaging Research Center (MIRCen), F-92260 Fontenay-auxRoses, France. ${ }^{4}$ Centre National de la Recherche Scientifique (CNRS), Université Paris-Sud, Université Paris-Saclay, UMR 9199, Neurodegenerative Diseases Laboratory, F-92260 Fontenayaux-Roses, France.
\end{abstract}

\#Corresponding author: Deniz Dalkara (deniz.dalkara@gmail.com, +33153462532). Vision Institute, 17 rue Moreau, Paris, 75012, France 


\section{Abstract}

Recently, we described a modified AAV2 vector-AAV2-7m8- having a capsid-displayed peptide insertion of 10 amino acids with enhanced retinal transduction properties. The insertion of the peptide referred to as $7 \mathrm{~m} 8$ is responsible for high-level gene delivery into deep layers of the retina when virus is delivered into the eye's vitreous. Here, we further characterize AAV2-7m8 mediated gene delivery to neural tissue and investigate the mechanisms by which the inserted peptide provides better transduction away from the injection site. First, in order to understand if the peptide exerts its effect on its own or in conjunction with the neighboring amino acids, we inserted the $7 \mathrm{~m} 8$ peptide at equivalent positions on three other AAV capsids, AAV5, AAV8, and AAV9, and evaluated its effect on their infectivity. Intravitreal delivery of these peptide insertion vectors revealed that only AAV9 benefited from $7 \mathrm{~m} 8$ insertion in the context of the retina. We then investigated AAV2-7m8 and AAV9-7m8 properties in the brain, to better evaluate the spread and efficacy of viral transduction in view of the peptide insertion. While $7 \mathrm{~m} 8$ insertion led to higher intensity gene expression, the spread of gene expression remained unchanged compared to the parental serotypes. Our results indicate that the $7 \mathrm{~m} 8$ peptide insertion acts by increasing efficacy of cellular entry, with little effect on the spread of viral particles in neural tissue. The effects of peptide insertion are capsid and tissue dependent, highlighting the importance of the microenvironment in gene delivery using AAV.

\section{Introduction}

Adeno-associated viruses (AAVs) are small (25nm in diameter) non-enveloped viruses of icosahedral structure belonging to the Dependovirus genus of the Parvoviridae family. They are single-stranded DNA viruses with $\sim 4.7$ kilobases carrying capacity and their infectious life cycle depends on helper viruses such as adeno-, herpes- or papillomaviruses. Recombinant AAV 
vectors have a low immunogenicity and an excellent safety profile, providing long-term therapeutic gene expression, important for clinical application in gene therapy. Not surprisingly, AAVs are currently the vectors of choice and have been used successfully in the treatment of hemophilia (Nathwani et al., 2011; Nathwani et al., 2014) and in retinal degeneration (Bainbridge et al., 2008; Cideciyan et al., 2008; Maguire et al., 2008). Retinal gene therapy has been successful in the treatment of Leber congenital amaurosis (LCA) (Bainbridge et al., 2008; Cideciyan et al., 2008; Maguire et al., 2008) and choroideremia (MacLaren et al., 2014) -although for LCA the benefits were limited in time (Bainbridge et al., 2015; Jacobson et al., 2015). However, first generation vector technology used in these clinical trials needs improvements, for better efficacy and for widespread gene delivery to the neural retina. Vector engineers have thus been working on improving AAV for future applications in the neural retina over the past ten years (Vandenberghe and Auricchio, 2012).

The efficacy of AAV-mediated gene delivery to retinal cells is an intricate equation involving viral dose, administration route, disease state, animal model and viral capsid. These aforementioned parameters determine the ability of AAV to transduce various retinal cell types the key cell targets in inherited retinal degeneration being the photoreceptors and the retinal pigmented epithelium (RPE) cells. Local ocular administration routes include subretinal and intravitreal delivery. Subretinal injections are most commonly used to access the outer retina, where vector is injected between photoreceptor and RPE cells. These cause a reversible retinal detachment and lead to high-level transduction in adjacent cells. One of the benefits of this administration route is the immune privilege in this compartment. AAV2, -5, -7, -8, -9 have been successful in gene transfer to photoreceptors when delivered into the subretinal space (Allocca et al., 2007; Auricchio et al., 2001; Mowat et al., 2014; Natkunarajah et al., 2008). However, retinal detachment can be associated with mechanical damage, especially in the fragile degenerating 
retina (Jacobson et al., 2012). The second administration route is intravitreal delivery, which deposits the vector dose in the vitreous- the gel-filled cavity of the eye. Intravitreal delivery is surgically simpler and can deliver genes pan-retinally in the rodent retina without surgical damage. However, natural AAVs cannot reach deep retinal layers when delivered into the vitreous, which usually prevents the use of this delivery route for outer retinal gene therapy. Naturally occurring AAV2 is highly efficient for pan-retinal transduction of the inner retina (Dalkara et al., 2013), directly exposed to the viral particles. But the photoreceptors and the RPE are not efficiently targeted by natural AAVs as they are buried under inner retinal neurons. Furthermore, the inner limiting membrane (ILM) -rich in AAV binding sites and composed of polysaccharides- acts as a strong physical diffusive barrier that limits AAV particles' access to the retina, thereby hampering retinal transduction efficiency from the vitreous (Dalkara et al., 2009). It has been shown that the vitreoretinal junction is a serotype-specific obstacle for $\mathrm{AAV}$, and the abundance of AAV receptors on the ILM is potentially a factor that controls diffusion across this barrier (Dalkara et al., 2009).

To overcome these issues, various AAV engineering approaches have been used to create vectors capable of transducing the entire retina through intravitreal injections (Cronin et al., 2014; Dalkara et al., 2013; Petrs-Silva et al., 2009; Petrs-silva et al., 2011). One photoreceptor permissive variant was obtained using an in vivo directed evolution approach (Dalkara et al., 2013). In this study, a large library of laboratory-generated capsid variants was subjected to selective pressure for their ability to penetrate into the photoreceptor layer of the mouse retina when injected into the vitreous. The successful variant isolated from this screen, called AAV2$7 \mathrm{~m} 8$, is characterized by a 10 -amino acid peptide 'LALGETTRPA', referred to as ' $7 \mathrm{~m} 8$ ', inserted at position 588 of the AAV2 capsid protein sequence. The insertion is composed of a variable heptamer (LGETTRP) region and 3 amino acids used as linkers for creating the library from 
which the variant was chosen. This new vector, AAV2-7m8, was recently used for therapeutic inner and outer retinal gene delivery in various animal models of retinal disease leading to successful proof-on-concept gene therapies (Byrne et al., 2014; Byrne et al., 2015; Dalkara et al., 2013; Macé et al., 2014).

Directed evolution does not require understanding of AAV's structure-function biology, as it uses an unbiased selection approach. However, it is worth studying the viral variants resulting from such screens to obtain further information on their mechanisms of enhanced transduction. The heptamer peptide (LGETTRP), inserted into the loop IV of AAV2, is responsible for the enhanced retinal transduction properties of AAV2-7m8 over its parental serotype AAV2. In this study, we set out to decipher the mechanisms by which $7 \mathrm{~m} 8$ provides increased retinal transduction. We asked whether the peptide exerts an effect on its own or does it synergize with its surrounding amino-acid environment? To address this question, we generated AAV5, -8, and 9 (AAV9/Hu.14) vectors displaying the $7 \mathrm{~m} 8$ peptide at the residues corresponding to AAV2's 588 residue (in loop IV) on their respective capsids. We found that $7 \mathrm{~m} 8$ insertion improved retinal transduction properties of AAV9 when virus is administered into the vitreous, as previously observed with AAV2-7m8 compared to AAV2. Peptide insertion had no positive effect on the retinal transduction properties of AAV5 or -8 after intravitreal injection. Subsequent intracerebral administration allowed an unbiased comparison of AAV2-7m8's diffusion versus increased infectivity, which could not be fully addressed in the retina because of the limited thickness of the tissue and the presence of the ILM as an additional diffusive barrier. This data together with data obtained in vitro, indicate that $7 \mathrm{~m} 8$ improves the vectors' infectivity rather than tissue diffusion. Altogether, our results suggest that $7 \mathrm{~m} 8$ peptide exerts its effects in synergy with surrounding amino acids, and effects of such insertions on various capsids are dependent on tissue and cellular environment. 


\section{Results}

\section{Molecular modeling of AAV2 and AAV2-7m8}

AAV2-7m8 is characterized by the insertion of a 10 amino-acid peptide 'LALGETTRPA' referred to as '7m8' (Fig.1B-D) composed of a heptamer (LGETTRP) and 3 amino acids as linkers, all inserted in the loop IV. The arginines R585 and R588 interact with each other and are involved in binding to the heparan sulfate proteoglycan (HSPG) (Fig.1D) (Kern et al., 2003; Opie et al., 2003). The $7 \mathrm{~m} 8$ peptide insertion in position 588 impedes this interaction (Fig.1D) thus reducing interactions between the virus and HSPG. Since HSPG is abundant on the inner limiting membrane (ILM) -the dense network of glycosaminoglycans between the vitreous and the retinawe hypothesized that AAV2's strong interaction with the HSPG of the ILM limits its diffusion into the retina. Accordingly, AAV2-7m8's reduced affinity for HSPG might increase passage through the ILM, partially accounting for increased retinal penetration. Alternatively, the $7 \mathrm{~m} 8$ peptide can exert an effect on its own, by interacting with another cell-surface glycan. To tease apart the effect of $7 \mathrm{~m} 8$ insertion from the properties of AAV2 capsid (such as HSPG binding), we decided to insert this peptide onto other AAV capsids and evaluate how the behavior of vectors change in view of the peptide insertion.

\section{Generation of $7 \mathrm{m8}$ inserted AAV serotypes 5, 8 and 9}

To better investigate the effects of $7 \mathrm{~m} 8$ insertion, we incorporated $7 \mathrm{~m} 8$ onto the capsid of 3 other AAVs (Fig. 2A). We used previously reported potential capsid regions amenable for the insertion of the $7 \mathrm{~m} 8$ peptide that may re-direct the natural viral tropism (Fig. 2B-E) (Boerner K. et al., [307] Rational Development of 12 Different AAV Serotypes as Scaffolds for Peptide Display. At: Annual meeting of Am. Soc. Gene and Cell Ther. New Orleans, 2015) (Koerber et al., 2007; Michelfelder et al., 2011). We hypothesized that the $7 \mathrm{~m} 8$ peptide may improve transduction on its own or in conjunction with its surrounding amino acids. AAV2, $-5,-8$ and -9 vectors displaying 
the $7 \mathrm{~m} 8$ peptide "LALGETTRPA" were generated and molecular models of the capsid monomers were generated using the Robetta prediction software. The molecular models show the 3D changes of each AAV monomer (Fig. 2A-E) after 7m8 insertion, which mainly affects the structure of loops III and IV. The RepCap plasmids generated after DNA sequence synthesis and cloning were then used for AAV production. In parallel, we produced control AAVs of each serotype with no peptide insertion and another scrambled peptide insertion variant where random 10 amino acids are inserted at the identical location as $7 \mathrm{~m} 8$ peptide on the AAV2 capsid (Table S1). All AAVs generated encoded for GFP under the control of a ubiquitous CAG promoter. Genomic titers were comparable between the parental serotypes and their $7 \mathrm{~m} 8$ modified variants (Table S1), suggesting that $7 \mathrm{~m} 8$ peptide insertion did not significantly impair genome packaging and capsid stability.

\section{Infectivity of $7 \mathrm{m8}$ modified vectors in vitro}

We aimed to test the infectivity and receptor binding properties of the newly generated peptide insertion vectors compared to their parental serotypes on relevant cell types, in vitro. In vitro transduction assays allow us to study the efficiency of the vectors in overcoming cellular barriers (cell entry and nuclear localization) in absence of more complex extracellular barriers, present in vivo. To this aim, HEK293T cells were infected at a MOI of 5000 with each vector and viral DNA was extracted 22 hours after infection. Viral genomes extracted from each condition were quantified using qRT-PCR (Fig. 3). We detected higher amounts of viral DNA within the infected cells for AAV2-7m8 - concurring with our previous observations (Dalkara et al., 2013)- and for AAV9-7m8 compared to their respective parental vectors, whereas less infection was observed for AAV5-7m8 compared to AAV5. The infectivity was similar between AAV8 and AAV8-7m8. As the amount of genomes present inside the cells does not directly reflect if the peptide insertion improves cell entry, or intracellular trafficking; we conducted a follow-up microscopy study for 
AAV2 versus its $7 \mathrm{~m} 8$ variant to gain further insight into how the $7 \mathrm{~m} 8$ peptide influences infectivity. We used a commercially available antibody (A20) to detect AAV capsids in HEK cells. HEK cells were infected with either AAV2 or AAV2-7m8 and viral particles were tracked by microscopy essentially as described by Bartlett and coworkers (Bartlett et al., 2000). Negative controls without viral particles were used to calibrate images and remove background. Confocal images of individual cells infected with the vectors were then processed to visualize the amount of viral particles present inside the cells versus in the nucleus (Fig. 3 and Supplemental Movies 1 and 2)

Lastly, to better understand whether the insertion site of the peptide is critical in the resulting capsid's properties, we next generated alanine substitution mutants of each serotype where the residues responsible for receptor binding are mutated (Schmidt et al., 2008). Since each of the serotypes we tested bind different primary receptors via different capsid regions, we blocked the regions responsible for cell binding for each serotype to mimic the theoretical mechanism of AAV2 HSPG-ablation. This was done for each serotype except for AAV8 whose primary receptor is currently unknown. These alanine substitution mutants are described in Table S1. The resulting vectors were tested for their infectious properties in vitro on HEK (for AAV2), 661W (for AAV5) or CHO Lec2 (for AAV9) cell lines permissive for each serotype vector (Supplemental Fig. 1). We found that mutating the receptor binding sites abolished the infectivity of the vectors (with the exception of AAV2 which retained some infectivity). For AAV5, the mutated residues were also those surrounding the peptide insertion, suggesting that disrupting the receptor binding site by peptide insertion or mutagenesis both impede viral infection. For AAV9, we have shown through galactose competition transduction assay that the peptide insertion does not impede galactose binding (See Supplemental Fig. 2). AAV9-7m8 retains AAV9's ability to bind galactose while 
displaying significantly increased transduction on both $\mathrm{CHO}$ Lec2 and HEK cell lines (Supplemental Fig. 1 and Fig. 6).

\section{Retinal transduction patterns of AAV2, 5, 8 and 9, compared to their $7 \mathrm{m8}$ insertion variants}

Next, we questioned whether the LALGETTRPA sequence is responsible for the increased uptake of AAV2-7m8 or if having any peptide insertion at the same location results in similar transduction behavior in vitro and in vivo. A scrambled 10 amino acid sequence (AAKKTIENRA) was inserted at the same site on AAV2 capsid as the $7 \mathrm{~m} 8$. Insertion of this scrambled sequence had no beneficial effect on the AAV2 capsid's transduction efficiency in vivo or in vitro on HEK cells (Fig. 4). To assess the retinal tropism of the AAV variants described above, we analyzed GFP expression after intravitreal injections by eye fundus examination (Fig. 4A and 5). For in vivo experiments, 6 eyes of C57BL/6J mice were injected bilaterally with $10^{10}$ vg per eye of each vector encoding GFP under the ubiquitous CAG promoter. 6 weeks after injection eye fundus exams were conducted to evaluate the extent of GFP expression in treated retinas. Each peptide insertion variant was compared to its parental serotype. In agreement with the in vitro results (Fig. 3A), insertion of $7 \mathrm{~m} 8$ did not seem to modify retinal transduction by AAV8, while it had a positive influence when inserted into the AAV2 and AAV9 capsids. $7 \mathrm{~m} 8$ insertion weakened retinal transduction of AAV5 (Fig.5).

We then focused our analysis on the variants with improved transduction patterns in the retina: AAV2-7m8, AAV9-7m8, and their parental capsids for further in vivo studies. Specifically, we investigated the capacity of AAV9-7m8 to transduce deep retinal layers. We wondered if AAV9$7 \mathrm{~m} 8$ was also capable of reaching deep retinal layers as observed with AAV2-7m8. Using the CAG promoter, the expression in Müller glial cells often convolutes the interpretation of results concerning viral penetration as Müller cells span the entire retina making it difficult to distinguish 
infected cell types. We therefore evaluated potential photoreceptor transduction with AAV9 and its $7 \mathrm{~m} 8$ variant under a rhodopsin promoter (Allocca et al., 2007) (Fig. 6). In this experiment, GFP expression was observed in photoreceptors using the AAV9-7m8. AAV9 did not transduce the photoreceptors in the central and peripheral areas. $7 \mathrm{~m} 8$ thus improves both AAV2 and AAV9 transduction from the vitreous.

Lastly, the same vectors were tested for their ability to transduce the retina when injected subretinally (Supplemental Fig. 3). This comparison revealed results mostly in line with the previous in vitro and in vivo results. Cellular tropism of the new vectors did not seem to be modified with respect to their parental serotypes (Supplemental Fig. 4).

\section{Cerebral transduction patterns of AAV2 and 9, compared to their $7 \mathrm{m8}$ insertion variants}

One of our initial questions was whether $7 \mathrm{~m} 8$ improved the tissue diffusion properties and/or infectivity of AAV2. To test this we performed stereotactic injections in another neural tissue -the brain parenchyma- to better evaluate spreading of the different vectors from the site of injection. We performed bilateral intra-striatal injections of $5 \times 10^{10} \mathrm{vg}$ for each vector into brains of C57BL/6J mice ( $\mathrm{n}=5$ mice were injected for each vector). Mice were sacrificed 6 weeks after injections and sagittal cryosections were prepared for examination with Nanozoomer technology at 20x resolution. Our results show that the spread of viral particles was not altered between the peptide insertion vectors and their parental serotypes as indicated by area of GFP expression (Fig. 7B). AAV2 and AAV2-7m8 lead to GFP expression in a relatively small zone around the injection site (Fig. 7 A, B), whereas both AAV9 and AAV9-7m8 lead to GFP expression in a broader zone (Fig. 7 A, B). Regarding expression intensity, AAV2-7m8 resulted in significantly higher intensity GFP compared to its parental serotype AAV2. Interestingly, intensity of gene expression calculated as mean gray value was reduced with AAV9-7m8 compared to AAV9. Our results collectively suggest that the effects of $7 \mathrm{~m} 8$ insertion depend on the viral capsid on which it 
is inserted and for AAV2-7m8, the peptide insertion provides better infectivity rather than better spread in neural tissue.

The discrepancy between the cerebral versus in vitro expression with AAV9-7m8 is possibly due to the saturation of the extent of expression using AAV9 in this brain region (Cearley and Wolfe, 2006). Indeed, AAV9 already performs very well in brain transduction, thereby making it difficult to show increase in intensity under the experimental conditions we used. Furthermore, the number of particles we used in our study might lead to toxic GFP expression levels with the more infectious AAV9-7m8 variant compared to AAV9-GFP (Klein et al., 2006; Vandenberghe et al., 2011) leading to a reduction in expression.

\section{Discussion}

Subretinal delivery is the most common administration route to target deep retinal layers involved in inherited retinal degenerations, but intravitreal injections can be preferable because they are less invasive, provide broader coverage and are surgically simpler. AAV vectors that are capable of efficient retinal transduction from the vitreous have been designed only recently, using rational design (Petrs-silva et al., 2011) or in vivo directed evolution (Cronin et al., 2014; Dalkara et al., 2013). In the latter study, we used directed evolution of random peptide libraries displayed on AAV2 capsid for selection of capsid variants that overcome the natural AAV transduction barriers of retinal tissue from the vitreous.

Here we wanted to understand the mechanisms by which $7 \mathrm{~m} 8$ peptide insertion enhances gene delivery to deeper layers of retinal tissue. Thanks to this peptide insertion, AAV2-7m8 outperforms other AAV variants thus far described for retinal transduction from the vitreous in the mouse and in the non-human primate retina (Dalkara et al., 2013) but it was not clear whether this performance was the result of better diffusion across extracellular barriers (i.e. ILM and extracellular matrix) and/or better cellular/nuclear entry (Figure 8). Moreover, it was not clear 
whether the peptide itself was responsible for these properties and if it exerted its effects in conjunction with its amino-acid microenvironment. The first aim of this study was thus to investigate whether the $7 \mathrm{~m} 8$ peptide could change AAV5, -8 , and -9 properties when inserted at equivalent sites within these capsids. Second, we aimed to better understand the effects of $7 \mathrm{~m} 8$ insertion on the two AAV capsids for which transduction was increased: was this increase due to better spread of viral particles and/or better infectivity?

First, we confirmed that the $7 \mathrm{~m} 8$ peptide sequence was responsible for the increased transduction properties of AAV2-7m8, as a scrambled peptide sequence inserted at the same location did not provide a similar increase in transduction. We found that $7 \mathrm{~m} 8$ insertion was compatible with capsid assembly of all AAV serotypes studied with no significant reduction in viral titers upon production by transient transfection of $293 \mathrm{~T}$ cells. However, $7 \mathrm{~m} 8$ insertion had different effects on each of the viral capsids. These results suggest that $7 \mathrm{~m} 8$ exerts its effects in conjunction with its amino-acid environment, working well with some amino acids and not with others. The insertion improved AAV2 and AAV9's transduction properties in the retina. The other vectors did not benefit from $7 \mathrm{~m} 8$ insertion. These findings are consistent with previous studies that demonstrate that peptide functionality is largely determined by the capsid scaffold, thus preventing a direct transfer of lead sequences from AAV2 onto other capsids and rather requiring a firsthand selection for each new serotype (Grimm et al., 2008; Michelfelder et al., 2011; Varadi et al., 2012; Ying et al., 2010).

The increase in infectivity of AAV2-7m8 and AAV9-7m8 were observed both in vivo, in the retina and in vitro on HEK cells and CHO Lec2 cells. AAV9-7m8 gave better results than its parental serotype AAV9 in the retina but was nevertheless less efficient in providing photoreceptor transduction compared to AAV2-7m8. One factor that could explain the performance of AAV2$7 \mathrm{~m} 8$ in the retina is its interactions with HSPG and therefore the ILM and ganglion cell layer 
(GCL). It is well established that peptide insertion at the position 587-588 of AAV2 capsid sequence induces a reduced HSPG binding phenotype (Dalkara et al., 2013; Lochrie et al., 2006; Opie et al., 2003; Wu et al., 2000), which is also the case for AAV2-7m8 mutant (Dalkara et al., 2013). It is thus possible that $7 \mathrm{~m} 8$ improved AAV2's access to the deeper retinal layers by reducing interactions with HSPG, which is abundant in the ILM and GCL (Clark et al., 2011) (Figure 7). Several previous studies established that reduced HSPG binding leads to increased transduction volumes in the CNS (Arnett et al., 2013; Nguyen et al., 2001). It remains unclear why reduced HSPG binding did not allow increased transduction volume for AAV2-7m8 when vector was delivered into the striatum. Unlike mutants deficient in HSPG binding, AAV2-7m8 has other new properties arising from the insertion of the peptide. We think these other properties (which might include binding to a currently unidentified cell-surface glycan) might counterbalance diffusion that would have been afforded by reduced HSPG binding.

AAV2 binds HSPG through its interaction with the amino acids R585 and R588 (required for binding), in addition to R475, R484 and K532. In a large number of studies the 587/588 position was chosen for insertional mutagenesis to redirect AAV2 tropism mainly leading to a reducedHSPG binding phenotype (Dalkara et al., 2013; Perabo et al., 2006). For AAV9, the amino acids N470, D271, N272, Y446, and W503 form a pocket required for galactose binding (Bell et al., 2012). In addition, the ${ }^{512} \mathrm{NGR}^{514}$ sequence has been described as an integrin recognition motif (Shen et al., 2014). The insertion site for $7 \mathrm{~m} 8$ in our study was the 588/589 position, which according to the previous studies is not necessary for galactose binding. Thus, we can suppose that $7 \mathrm{~m} 8$ insertion did not affect galactose binding but improved viral cell entry/nuclear trafficking through another mechanism. AAV9 has remarkable properties for brain transduction compared to AAV2 and lack of HSPG binding likely facilitates its larger spread in neural tissue (Figure 6) (Zhang et al., 2011). Although AAV9-7m8 did not outperform AAV2-7m8 for 
transduction of the mouse retina, it could be interesting to compare the vectors' efficiency in the non-human primate retina since AAV9 has higher cone photoreceptor tropism than AAV2 and this cell type is of interest for gene therapy applications (Vandenberghe et al., 2013). Indeed the conerich fovea is a region that is accessible through intravitreal injections and AAV9-7m8 can display favorable properties at this site. Sialic acid is required for AAV5 binding and infection (Walters et al., 2004). Afione and collaborators have recently identified AAV5 sialic acid binding region (Afione et al., 2015), showing that mutation of amino acids 569 and 585 or 587 results in alteration of sialic acid-dependent transduction. In our study $7 \mathrm{~m} 8$ was made at the 575 position, which likely hampered sialic acid binding region and was detrimental to the vectors performance both in vivo and in vitro. On the other hand, AAV8's primary receptor is unknown. The 37-67-kDa laminin receptor (lamR) has been identified as its co-receptor and AAV8 binding to lamR is mediated by the amino acids 491 to 547 and 593 to 623 (Akache et al., 2006). Moreover, peptide insertions on AAV8 capsid at position 590 allow modification of its tropism (Michelfelder et al., 2011; Raupp et al., 2012) but amino acids 588 to 592 are not necessary for AAV8 binding and uptake. This region is thus involved in but not necessary for interaction with cellular receptors (Raupp et al., 2012). In our study the $7 \mathrm{~m} 8$ peptide was inserted around this region and we observed no significant improvement in AAV8's infectivity.

Lastly, our study sheds light onto the consequences of $7 \mathrm{~m} 8$ insertion on AAV2's gene transfer efficiency. Our data suggest that $7 \mathrm{~m} 8$ 'LALGETTRPA' peptide strongly improves AAV2 infectivity by increasing its efficacy in overcoming cellular barriers (mainly cell entry). The different effects of $7 \mathrm{~m} 8$ insertion on various serotypes' capsids can be explained by the complexity of capsid structure relationships of AAVs. The capsid structures of all the AAVs used in this study have been resolved by X-ray crystallography (AAV5, PDB id 3NTT; AAV8 (Nam et al., 2007), PDB id 2QA0; and AAV9 (DiMattia et al., 2012), PDB id 3UX1). Resolution of the 
different AAVs' capsid structures, identification of their primary or co-receptors, and mutational analyses of their receptor binding regions all deepen our understanding of this important vector's structure-function relationships. This knowledge is further enriched by the discovery of artificial serotypes through combinatorial screens and the mechanistic study of their properties.

\section{Experimental procedures}

\section{AAV vector production}

Recombinant AAVs were produced as previously described using the co-transfection method and purified by iodixanol gradient ultracentrifugation (Choi et al., 2007). Concentration and buffer exchange was performed against PBS containing 0.001\% Pluronic. AAV vector stocks titers were then determined based on real-time quantitative PCR titration method (Aurnhammer et al., 2011) using SYBR Green (Life Technologies).

\section{Structure analysis}

VP3 monomers of $7 \mathrm{~m} 8$ insertion vectors were generated using the Robetta modeling server (Chivian et al., 2003; Kim et al., 2004) and superimposed to their parental serotypes using UCSF Chimera (Pettersen et al., 2004).

\section{AAV cell entry and trafficking assays}

The protocol from Bartlett et al (Bartlett et al., 2000) was used with the following modifications: Cells were incubated with an MOI of 250000 of each vector. After 2 hours, cells were fixed and anti-AAV2 capsid antibody (A20 from American Research Products (Euromedex)) was used according to manufacturers instructions to reveal AAV particles. Cells were additionally labeled with phalloidin and DAPI. Confocal images were acquired using Olympus FV1000 Inverted confocal microscope at equal settings. To identify cellular localization of AAV particles, confocal images were processed with Imaris software (Bitplane). Several masks were created to isolate cellular compartments: DAPI counterstaining was used to define the nuclear zone. Phalloidin 
staining of the cell membrane allowed us to define the cytosolic compartment by subtraction of the nuclear zone from the membrane. Each mask was used to segment AAV immunostaining and spot detection was performed to quantify the amount of particles in different cellular compartments.

\section{Animals}

The experiments were realized in accordance with the National Institutes of Health Guide for Care and Use of Laboratory Animals and approved by local ethics committees.

For all experiments AAV vector stocks were titer adjusted by dilution in PBS containing 0.001\% Pluronic. For eye injections, mice were anesthetized by isofluorane inhalation. Pupils were dilated and 33-gauge needle was inserted into the eye to deliver $2 \mu \mathrm{L}$ of AAV vector solution $\left(10^{10} \mathrm{vg}\right)$ into the vitreous or $1 \mu \mathrm{L}$ subretinally. GFP expression was visualized using Micron III ophtalmoscope after dilation of the pupils and under isofluorane anesthesia. For intrastriatal injections, mice were anesthetized by intraperitoneal injection of ketamine $(100 \mathrm{mg} / \mathrm{kg})$ and xylazine $(10 \mathrm{mg} / \mathrm{kg})$ and placed on a stereotaxic frame (Köpf Apparatus). After skin incision, the skull was exposed to position injection cannulae at $+1 \mathrm{~mm}$ anteroposterior and $\pm 2 \mathrm{~mm}$ lateral relative to bregma. After drilling of the skull, the cannulae were lowered to $2.5 \mathrm{~mm}$ relative to the dura and $2 \mu \mathrm{l}$ of viral solution $\left(5 \times 10^{10} \mathrm{vg}\right)$ was injected in 8 minutes. The skin was sutured and mice monitored until complete awakening.

\section{Histology and microscopy}

Eyes were enucleated and immediately fixed in $4 \%$ paraformaldehyde (PFA) at $4^{\circ} \mathrm{C}$, for 20 min for flatmounts or for 2 hours for cryosections. For brain histology, mice were deeply anesthetized for trans-cardiac perfusion with ice-cold PBS followed by 4\% PFA in PBS. Brains were then removed and post-fixed for 4 hours in the same fixative. For cryosections, eye-cups and brains were immersed in PBS-30\% sucrose overnight at $4^{\circ} \mathrm{C}$. They were embedded in OCT medium and 
frozen in liquid nitrogen. Vertical sections were cut with a Microm cryostat and mounted in Vectashield mounting medium for fluorescence microscopy. Retinal flatmount images were acquired using a Leica DM6000 epifluorescence microscope and brain section images with Nanozoomer technology (Hamamatsu) and retinal sections were visualized using an Olympus IX81 and Olympus FV1000 Inverted confocal microscopes.

Quantification of AAV vector internalization in vitro using quantitative PCR

HEK 293 cells were plated onto 24-well plates coated with poly-L-lysine and cells were infected with various AAV vectors at 5,000 MOI. After 22 hours of incubation at $37^{\circ} \mathrm{C}$, cells were washed 3 times in PBS and viral DNA was harvested using a DNA-extraction kit (NucleoSpin Tissue, Macherey-Nagel). Relative genome quantification was performed through qPCR, using primers targeted against the GFP transgene and actin as the housekeeping gene.

\section{Quantification of AAV transduction using flow cytometry}

Cells were plated in 24 well plates at a concentration of 40,000 cells/well for Lec 2 or $661 \mathrm{~W}$ and 100,000 cells/well for HEK293s. The following day, they were infected with AAV vectors or a mix of AAV vector and PNA (Life Technologies). One day post infection, cells were dissociated with trypsine and fixed. 10000 cells per sample were counted and analyzed using a CytomicsFC500 flow cytometer (Beckman Coulter). Uninfected control cells were also counted and analyzed to establish transduction efficiency baselines. Data were obtained from 3-4 technical replicates for each vector with the exception of AAV9-7m8 alanine mutant where 2 technical replicates were used due to low viral titer.

\section{Statistical tests}

Data were analyzed using a Student t-test in Graphpad Prism. Error bars on the graphs show the Standard Error of the Mean (SEM). p values are expressed as the following ${ }^{*} \mathrm{p}<0.05,{ }^{* *} \mathrm{p}<0.01$, ${ }^{* * *} \mathrm{p}<0.001$ 


\section{Author contributions}

M.D. and H.K. created and produced the $7 \mathrm{~m} 8$ vectors. H.K. and G.W. conducted the in vivo experiments. M.D. and H.K. conducted and analyzed the in vitro experiments. C.W. created all of the alanine mutants and scrambled peptide insertion variant. S.F. designed and performed image analysis for subcellular localization of AAV. A-P.B helped design and execute experiments in the striatum, and gave feedback on the manuscript. J-A.S gave feedback on the manuscript and provided scientific input. D.D. designed and supervised the experiments. D.D. and H.K. wrote the manuscript.

\section{Acknowledgements}

We thank Giulia Spampinato and Anna Bochicchio for helpful discussions and advice. We also thank the Flow cytometry, Imaging and Animal facilities of the Institut de la Vision. We thank Arthur Planul for providing plasmids, Peggy Barbe for technical assistance. This study was supported by AFM-Téléthon, Marie Curie CIG (334130, RETINAL GENE THERAPY), INSERM, Labex-Lifesenses.

D.D. is an inventor on pending and issued patents related to AAV gene delivery, and a consultant for Gensight Biologics. J.-A.S. is a founder and consultant for Pixium Vision and GenSight Biologics and a consultant for Sanofi-Fovea and Genesignal. The other authors have no conflict of interest.

\section{References}

Afione S, DiMattia M a., Halder S, Di Pasquale G, Agbandje-McKenna M, Chiorini J a. 2015. Identification and Mutagenesis of the Adeno-Associated Virus 5 Sialic Acid Binding Region. J. Virol. 89:1660-1672.

Akache B, Grimm D, Pandey K, Yant SR, Xu H, Kay M a. 2006. The 37/67-kilodalton laminin receptor is a receptor for adeno-associated virus serotypes 8, 2, 3, and 9. J. Virol. 80:9831-6. 
http://www.pubmedcentral.nih.gov/articlerender.fcgi?artid=1617255\&tool=pmcentrez\&rend ertype $=$ abstract.

Allocca M, Mussolino C, Garcia-Hoyos M, Sanges D, Iodice C, Petrillo M, Vandenberghe LH, Wilson JM, Marigo V, Surace EM, Auricchio A. 2007. Novel adeno-associated virus serotypes efficiently transduce murine photoreceptors. J. Virol. 81:11372-80. http://www.pubmedcentral.nih.gov/articlerender.fcgi?artid=2045569\&tool=pmcentrez\&rend ertype $=$ abstract.

Arnett ALH, Beutler LR, Quintana A, Allen J, Finn E, Palmiter RD, Chamberlain JS. 2013. Heparin-binding correlates with increased efficiency of AAV1- and AAV6-mediated transduction of striated muscle, but negatively impacts CNS transduction. Gene Ther. 20:497-503.

http://www.pubmedcentral.nih.gov/articlerender.fcgi? artid=4004370\&tool=pmcentrez\&rend ertype $=$ abstract.

Auricchio A, Kobinger G, Anand V, Hildinger M, O’Connor E, Maguire AM, Wilson JM, Bennett J. 2001. Exchange of surface proteins impacts on viral vector cellular specificity and transduction characteristics: the retina as a model. Hum. Mol. Genet. 10:3075-3081. http://www.ncbi.nlm.nih.gov/pubmed/11751689.

Aurnhammer C, Haase M, Muether N, Hausl M, Rauschhuber C, Huber I, Nitschko H, Busch U, Sing A, Ehrhardt A, Baiker A. 2011. Universal Real-Time PCR for the Detection and Quantification of Adeno-Associated Virus Serotype 2-Derived Inverted Terminal Repeat Sequences. Hum. Gene Ther.

Bainbridge JWB, Smith AJ, Barker SS, Robbie S, Henderson R, Balaggan K, Viswanathan A, Holder GE, Stockman A, Tyler N, Petersen-Jones S, Bhattacharya SS, Thrasher AJ, Fitzke FW, Carter BJ, Rubin GS, Moore AT, Ali RR. 2008. Effect of gene therapy on visual function in Leber's congenital amaurosis. N. Engl. J. Med. 358:2231-9. http://www.ncbi.nlm.nih.gov/pubmed/18441371.

Bainbridge JWB, Mehat MS, Sundaram V, Robbie SJ, Barker SE, Ripamonti C, Georgiadis A, Mowat FM, Beattie SG, Gardner PJ, Feathers KL, Luong V a., Yzer S, Balaggan K, Viswanathan A, de Ravel TJL, Casteels I, Holder GE, Tyler N, Fitzke FW, Weleber RG, Nardini M, Moore AT, Thompson D a., Petersen-Jones SM, Michaelides M, van den Born LI, Stockman A, Smith AJ, Rubin G, Ali RR. 2015. Long-Term Effect of Gene Therapy on Leber's Congenital Amaurosis. N. Engl. J. Med.:150504083137004.

http://www.nejm.org/doi/abs/10.1056/NEJMoa1414221.

Bartlett JS, Wilcher R, Samulski RJ. 2000. Infectious entry pathway of adeno-associated virus and adeno-associated virus vectors. J. Virol. 74:2777-85.

http://www.pubmedcentral.nih.gov/articlerender.fcgi?artid=111768\&tool=pmcentrez\&render type $=$ abstract.

Bell CL, Gurda BL, Van Vliet K, Agbandje-McKenna M, Wilson JM. 2012. Identification of the Galactose Binding Domain of the Adeno-Associated Virus Serotype 9 Capsid. J. Virol.

86:7326-7333.

Byrne LC, Oztürk BE, Lee T, Fortuny C, Visel M, Dalkara D, Schaffer D V, Flannery JG. 2014. Retinoschisin gene therapy in photoreceptors, Müller glia or all retinal cells in the Rs1h-/mouse. Gene Ther.:1-8. http://www.ncbi.nlm.nih.gov/pubmed/24694538.

Byrne LC, Dalkara D, Luna G, Fisher SK, Clérin E, Sahel J, Léveillard T, Flannery JG. 2015. Viral-mediated RdCVF and RdCVFL expression protects cone and rod photoreceptors in retinal degeneration. J. Clin. Invest. 125:105-116. http://www.jci.org/articles/view/65654. Cearley CN, Wolfe JH. 2006. Transduction characteristics of adeno-associated virus vectors 
expressing cap serotypes 7, 8, 9, and Rh10 in the mouse brain. Mol. Ther. 13:528-37. http://www.nature.com.gate1.inist.fr/mt/journal/v13/n3/full/mt200664a.html.

Chivian D, Kim DE, Malmström L, Bradley P, Robertson T, Murphy P, Strauss CEM, Bonneau R, Rohl C a., Baker D. 2003. Automated Prediction of CASP-5 Structures Using the Robetta Server. Proteins Struct. Funct. Genet. 53:524-533.

Choi VW, Asokan A, Haberman R a, Samulski RJ. 2007. Production of recombinant adenoassociated viral vectors. Curr. Protoc. Hum. Genet. Chapter 12:Unit 12.9.

http://www.pubmedcentral.nih.gov/articlerender.fcgi?artid=3209619\&tool=pmcentrez\&rend ertype $=$ abstract.

Clark SJ, Keenan TDL, Fielder HL, Collinson LJ, Holley RJ, Merry CLR, van Kuppevelt TH, Day AJ, Bishop PN. 2011. Mapping the Differential Distribution of Glycosaminoglycans in the Adult Human Retina, Choroid, and Sclera. Investig. Opthalmology Vis. Sci. 52:6511. http://iovs.arvojournals.org/article.aspx?doi=10.1167/iovs.11-7909.

Cronin T, Vandenberghe LH, Hantz P, Juttner J, Reimann A, Kacsó A-E, Huckfeldt RM, Busskamp V, Kohler H, Lagali PS, Roska B, Bennett J. 2014. Efficient transduction and optogenetic stimulation of retinal bipolar cells by a synthetic adeno-associated virus capsid and promoter. EMBO Mol. Med.:1-16. http://www.ncbi.nlm.nih.gov/pubmed/25092770.

Dalkara D, Byrne LLC, Klimczak RR, Visel M, Yin L, Merigan WH, Flannery JG, Schaffer D V. 2013. In vivo-directed evolution of a new adeno-associated virus for therapeutic outer retinal gene delivery from the vitreous. Sci. Transl. Med. 5:189ra76.

http://www.ncbi.nlm.nih.gov/pubmed/23761039.

Dalkara D, Kolstad KD, Caporale N, Visel M, Klimczak RR, Schaffer D V, Flannery JG. 2009. Inner limiting membrane barriers to AAV-mediated retinal transduction from the vitreous. Mol. Ther. 17:2096-2102.

DiMattia M a., Nam H-J, Van Vliet K, Mitchell M, Bennett a., Gurda BL, McKenna R, Olson NH, Sinkovits RS, Potter M, Byrne BJ, Aslanidi G, Zolotukhin S, Muzyczka N, Baker TS, Agbandje-McKenna M. 2012. Structural Insight into the Unique Properties of AdenoAssociated Virus Serotype 9. J. Virol. 86:6947-6958.

Grimm D, Lee JS, Wang L, Desai T, Akache B, Storm T a, Kay M a. 2008. In vitro and in vivo gene therapy vector evolution via multispecies interbreeding and retargeting of adenoassociated viruses. J. Virol. 82:5887-5911.

Jacobson SG, Cideciyan A V, Ratnakaram R, Heon E, Schwartz SB, Roman AJ, Peden MC, Aleman TS, Boye SL, Sumaroka A, Conlon TJ, Calcedo R, Pang J, Erger KE. 2012. Gene Therapy for Leber Congenital Amaurosis caused by RPE65 mutations: Safety and Efficacy in Fifteen Children and Adults Followed up to Three Years. Arch. Ophthalmol. 130:9-24.

Jacobson SG, Cideciyan A V., Roman AJ, Sumaroka A, Schwartz SB, Heon E, Hauswirth WW. 2015. Improvement and Decline in Vision with Gene Therapy in Childhood Blindness. $N$. Engl. J. Med.:150503141523009. http://www.nejm.org/doi/abs/10.1056/NEJMoa1412965.

Kern a, Schmidt K, Leder C, Müller OJ, Wobus CE, Lieth CW Von Der, King J a, Mu OJ, Bettinger K. 2003. Identification of a Heparin-Binding Motif on Adeno-Associated Virus Type 2 Capsids Identification of a Heparin-Binding Motif on Adeno-Associated Virus Type 2 Capsids. J. Virol. 77:11072-11081.

Kim DE, Chivian D, Baker D. 2004. Protein structure prediction and analysis using the Robetta server. Nucleic Acids Res. 32:526-531.

Klein RL, Dayton RD, Leidenheimer NJ, Jansen K, Golde TE, Zweig RM. 2006. Efficient neuronal gene transfer with AAV8 leads to neurotoxic levels of tau or green fluorescent proteins. Mol. Ther. 13:517-27. 
http://www.pubmedcentral.nih.gov/articlerender.fcgi?artid=2987642\&tool=pmcentrez\&rend ertype $=$ abstract.

Koerber JT, Jang J-H, Yu JH, Kane RS, Schaffer D V. 2007. Engineering adeno-associated virus for one-step purification via immobilized metal affinity chromatography. Hum. Gene Ther. 18:367-78. http://www.ncbi.nlm.nih.gov/pubmed/17437357.

Lochrie M a, Tatsuno GP, Christie B, Mcdonnell JW, Zhou S, Pierce GF, Colosi P, Surosky R. 2006. Mutations on the External Surfaces of Adeno-Associated Virus Type 2 Capsids That Affect Transduction and Neutralization Mutations on the External Surfaces of AdenoAssociated Virus Type 2 Capsids That Affect Transduction and Neutralization. J. Virol. 80:821-834.

Macé E, Caplette R, Marre O, Sengupta A, Chaffiol A, Barbe P, Desrosiers M, Bamberg E, Sahel J-A, Picaud S, Duebel J, Dalkara D. 2014. Targeting channelrhodopsin-2 to ON-bipolar cells with vitreally administered AAV restores $\mathrm{ON}$ and OFF visual responses in blind mice. Mol. Ther. http://www.ncbi.nlm.nih.gov/pubmed/25095892.

MacLaren RE, Groppe M, Barnard AR, Cottriall CL, Tolmachova T, Seymour L, Clark KR, During MJ, Cremers FPM, Black GCM, Lotery AJ, Downes SM, Webster AR, Seabra MC. 2014. Retinal gene therapy in patients with choroideremia: initial findings from a phase $1 / 2$ clinical trial. Lancet 383:1129-1137. http:/www.ncbi.nlm.nih.gov/pubmed/24439297.

Maguire AM, Simonelli F, Pierce EA, Pugh EN, Mingozzi F, Bennicelli J, Banfi S, Marshall KA, Testa F, Surace EM, Rossi S, Lyubarsky A, Arruda VR, Konkle B, Stone E, Sun J, Jacobs J, Dell'Osso L, Hertle R, Ma J, Redmond TM, Zhu X, Hauck B, Zelenaia O, Shindler KS, Maguire MG, Wright JF, Volpe NJ, McDonnell JW, Auricchio A, High KA, Bennett J. 2008. Safety and efficacy of gene transfer for Leber's congenital amaurosis. N. Engl. J. Med. 358:2240-8.

http://www.pubmedcentral.nih.gov/articlerender.fcgi?artid=2829748\&tool=pmcentrez\&rend ertype $=$ abstract.

Michelfelder S, Varadi K, Raupp C, Hunger A, Körbelin J, Pahrmann C, Schrepfer S, Müller OJ, Kleinschmidt J a., Trepel M. 2011. Peptide ligands incorporated into the threefold spike capsid domain to re-direct gene transduction of AAV8 and AAV9 in vivo. PLoS One 6.

Mowat FM, Gornik KR, Dinculescu a, Boye SL, Hauswirth WW, Petersen-Jones SM, Bartoe JT. 2014. Tyrosine capsid-mutant AAV vectors for gene delivery to the canine retina from a subretinal or intravitreal approach. Gene Ther. 21:96-105.

Nam H-J, Lane MD, Padron E, Gurda B, McKenna R, Kohlbrenner E, Aslanidi G, Byrne B, Muzyczka N, Zolotukhin S, Agbandje-McKenna M. 2007. Structure of adeno-associated virus serotype 8, a gene therapy vector. J. Virol. 81:12260-12271.

Nathwani AC, Rosales C, McIntosh J, Rastegarlari G, Nathwani D, Raj D, Nawathe S, Waddington SN, Bronson R, Jackson S, Donahue RE, High K a, Mingozzi F, Ng CYC, Zhou J, Spence Y, McCarville MB, Valentine M, Allay J, Coleman J, Sleep S, Gray JT, Nienhuis AW, Davidoff AM. 2011. Long-term safety and efficacy following systemic administration of a self-complementary AAV vector encoding human FIX pseudotyped with serotype 5 and 8 capsid proteins. Mol. Ther. 19:876-885.

Nathwani AC, Reiss UM, Tuddenham EGD, Rosales C, Chowdary P, McIntosh J, Della Peruta M, Lheriteau E, Patel N, Raj D, Riddell A, Pie J, Rangarajan S, Bevan D, Recht M, Shen YM, Halka KG, Basner-Tschakarjan E, Mingozzi F, High K a., Allay J, Kay M a., Ng CYC, Zhou J, Cancio M, Morton CL, Gray JT, Srivastava D, Nienhuis AW, Davidoff AM. 2014. Long-Term Safety and Efficacy of Factor IX Gene Therapy in Hemophilia B. N. Engl. J. Med. 371:1994-2004. 
Natkunarajah M, Trittibach P, McIntosh J, Duran Y, Barker SE, Smith a J, Nathwani a C, Ali RR. 2008. Assessment of ocular transduction using single-stranded and self-complementary recombinant adeno-associated virus serotype 2/8. Gene Ther. 15:463-7. http://www.ncbi.nlm.nih.gov/pubmed/18004402.

Nguyen JB, Sanchez-Pernaute R, Cunningham J, Bankiewicz KS. 2001. Convection-enhanced delivery of AAV-2 combined with heparin increases TK gene transfer in the rat brain. Neuroreport 12:1961-4. http://www.ncbi.nlm.nih.gov/pubmed/11435930.

Opie SR, Warrington KH, Agbandje-McKenna M, Zolotukhin S, Muzyczka N. 2003. Identification of amino acid residues in the capsid proteins of adeno-associated virus type 2 that contribute to heparan sulfate proteoglycan binding. J. Virol. 77:6995-7006.

Perabo L, Goldnau D, White K, Endell J, Boucas J, Humme S, Work LM, Janicki H, Hallek M, Baker AH, Büning H. 2006. Heparan sulfate proteoglycan binding properties of adenoassociated virus retargeting mutants and consequences for their in vivo tropism. J. Virol. 80:7265-9. http://www.pubmedcentral.nih.gov/articlerender.fcgi?artid=1489073\&tool=pmcentrez\&rend ertype $=$ abstract.

Petrs-silva H, Dinculescu A, Li Q, Deng W, Pang J, Min S, Chiodo V, Neeley AW, Govindasamy L, Bennett A, Agbandje-McKenna M, Zhong L, Li B, Jayandharan GR, Srivastava A, Lewin AS, Hauswirth WW. 2011. Novel properties of tyrosine-mutant AAV2 vectors in the mouse retina. Mol. Ther. 19:293-301.

http://www.pubmedcentral.nih.gov/articlerender.fcgi? artid=3034844\&tool=pmcentrez\&rend ertype $=$ abstract.

Petrs-Silva H, Dinculescu A, Li Q, Min S-H, Chiodo V, Pang J-J, Zhong L, Zolotukhin S, Srivastava A, Lewin AS, Hauswirth WW. 2009. High-efficiency transduction of the mouse retina by tyrosine-mutant AAV serotype vectors. Mol. Ther. 17:463-71. http://www.pubmedcentral.nih.gov/articlerender.fcgi?artid=2835095\&tool=pmcentrez\&rend ertype $=$ abstract.

Pettersen EF, Goddard TD, Huang CC, Couch GS, Greenblatt DM, Meng EC, Ferrin TE. 2004. UCSF Chimera - A visualization system for exploratory research and analysis. J. Comput. Chem. 25:1605-1612.

Raupp C, Naumer M, Muller OJ, Gurda BL, Agbandje-McKenna M, Kleinschmidt J a. 2012. The Threefold Protrusions of Adeno-Associated Virus Type 8 Are Involved in Cell Surface Targeting as Well as Postattachment Processing. J. Virol. 86:9396-9408.

Schmidt M, Govindasamy L, Afione S, Kaludov N, Agbandje-McKenna M, Chiorini JA. 2008. Molecular characterization of the heparin-dependent transduction domain on the capsid of a novel adeno-associated virus isolate, AAV(VR-942). J. Virol. 82:8911-6. http://www.pubmedcentral.nih.gov/articlerender.fcgi? artid=2519687\&tool=pmcentrez\&rend ertype $=$ abstract.

Shen S, Berry GE, Castellanos Rivera RM, Cheung RY, Troupes AN, Brown SM, Kafri T, Asokan A. 2014. Functional analysis of the putative integrin recognition motif on adenoassociated virus 9. J. Biol. Chem. 290:1496-1504.

Vandenberghe LH, Auricchio a. 2012. Novel adeno-associated viral vectors for retinal gene therapy. Gene Ther. 19:162-8. http://www.ncbi.nlm.nih.gov/pubmed/21993172.

Vandenberghe LH, Bell P, Maguire AM, Cearley CN, Xiao R, Calcedo R, Wang L, Castle MJ, Maguire AC, Grant R, Wolfe JH, Wilson JM, Bennett J. 2011. Dosage thresholds for AAV2 and AAV8 photoreceptor gene therapy in monkey. Sci. Transl. Med. 3:88ra54. http://www.ncbi.nlm.nih.gov/pubmed/21697530. 
Vandenberghe LH, Bell P, Maguire AM, Xiao R, Hopkins TB, Grant R, Bennett J, Wilson JM. 2013. AAV9 targets cone photoreceptors in the nonhuman primate retina. PLoS One 8:e53463.

http://www.pubmedcentral.nih.gov/articlerender.fcgi? artid=3559681\&tool=pmcentrez\&rend ertype $=$ abstract.

Varadi K, Michelfelder S, Korff T, Hecker M, Trepel M, Katus H a, Kleinschmidt J a, Müller OJ. 2012. Novel random peptide libraries displayed on AAV serotype 9 for selection of endothelial cell-directed gene transfer vectors. Gene Ther. 19:800-9. http://www.ncbi.nlm.nih.gov/pubmed/21956692.

Walters RW, Agbandje-mckenna M, Valorie D, Moninger TO, Olson NH, Chiorini J a, Baker TS, Bowman VD, Seiler M, Zabner J. 2004. Structure of Adeno-Associated Virus Structure of Adeno-Associated Virus Serotype 5 78:3361-3371.

Wu P, Xiao W, Conlon T, Hughes J, Agbandje-McKenna M, Ferkol T, Flotte T, Muzyczka N. 2000. Mutational analysis of the adeno-associated virus type 2 (AAV2) capsid gene and construction of AAV2 vectors with altered tropism. J. Virol. 74:8635-8647.

Ying Y, Müller OJ, Goehringer C, Leuchs B, Trepel M, Katus H a, Kleinschmidt J a. 2010. Hearttargeted adeno-associated viral vectors selected by in vivo biopanning of a random viral display peptide library. Gene Ther. 17:980-90.

http://www.ncbi.nlm.nih.gov/pubmed/20393510.

Zhang H, Yang B, Mu X, Ahmed SS, Su Q, He R, Wang H, Mueller C, Sena-Esteves M, Brown R, Xu Z, Gao G. 2011. Several rAAV vectors efficiently cross the blood-brain barrier and transduce neurons and astrocytes in the neonatal mouse central nervous system. Mol. Ther. 19:1440-8. http://www.pubmedcentral.nih.gov/articlerender.fcgi?artid=3149178\&tool=pmcentrez\&rend ertype $=$ abstract.

\section{Figure Legends}

Figure 1: Structural model of AAV2-7m8 capsid and proposed mechanism for the influence of $7 \mathrm{m8}$ peptide insertion on HSPG binding. (A) Superposition of the 60 monomers forming AAV2 capsid (dark blue) and one monomer of AAV2-7m8 (red) containing the insertion LALGETTRPA (shown in cyan). (B) Superposition of AAV2 and AAV2-7m8 capsid monomers. (C) Zoom onto the $7 \mathrm{~m} 8$ insertion (cyan) in loop IV. (D) Model for the effect of $7 \mathrm{~m} 8$ insertion on HSPG binding. Schematic for AAV2 or AAV2-7m8 loop IV (top) and three-dimensional atomic structure of the 587 region with focus on the interaction between the arginines (R). In the AAV2 capsid, the two arginines (R585 and R588 indicated as R) interact with each other and are part of 
the heparin-binding motif. In the AAV2-7m8 variant, $7 \mathrm{~m} 8$ disrupts the HSPG-binding motif, taking the arginines apart. Molecular models were generated using UCSF Chimera (Pettersen et al. 2004).

\section{Figure 2: Sequence and structural representation of AAV2, 5, 8 and 9 after $7 \mathrm{m8}$ insertion.}

(A) Schematic representation of the AAV packaging plasmids with the peptide insertion sites indicated in blue. (B-E) The wild-type AAV monomers of AAV2 (B), AAV5 (C), AAV8 (D) and AAV9 (D) are represented in white, and their corresponding $7 \mathrm{~m} 8$ variants in red. The $7 \mathrm{~m} 8$ peptide is shown in blue for each capsid. Molecular models were generated using UCSF Chimera (Pettersen et al. 2004). Rep: Replication, Cap: Capsid.

Figure 3: Effect of $7 \mathrm{m8}$ insertion on transduction efficiency. (A) Fold increase in intracellular DNA levels with 7m8 modified AAV2, 5, 8 and 9- vectors with respect to unmodified serotypes. DNA was extracted from HEK cells infected with MOI of 5000 for each vector encoding GFP 22 hours post infection. Infections were performed in triplicates. After $\mathrm{qPCR}$, the relative quantitation method was used to calculate fold differences in GFP expression by $7 \mathrm{~m} 8$ modified vectors normalized against each parental serotype. (B) Nuclear, (C) Cytosolic and (D) Intracellular localization of AAV2 and AAV2-7m8 particles calculated as number of spots from $\mathrm{n}=4$ cells for AAV2 and $\mathrm{n}=5$ cells for AAV2-7m8 analyzed by Imaris after 3D reconstructions shown in $\mathrm{E}$ and $\mathrm{F}$. Image stacks were acquired with confocal microscopy using the same acquisition parameters, calibrated to control images. A representative z-projection of a stack is shown for each vector in the first columns of E and F. Localization of the spots with respect to cellular compartments represented in 3D are shown for each cell in columns 2 to 5 . Scale bars are $5 \mu \mathrm{m}$. 
Figure 4: The effect of $7 \mathrm{m8}$ peptide insertion on AAV2 capsid compared to a random scrambled peptide insertion at identical position. (A) Eye fundus imaging at equal settings 3 weeks after intravitreal injection of AAV2 (n=3), AAV2-scramble (AAKKTIENR) (n=3) or AAV2-7m8 (LALGETTRPA) (n=3). (B) GFP cDNA was extracted from retinas at 4 weeks after injection. Relative cDNA from each sample was measured by qRT-PCR and expressed as foldincrease relative to AAV2. (C) Transduction efficiency of AAV2, AAV2-scramble and AAV2$7 \mathrm{~m} 8$ on HEK cells measured by flow cytometry. GFP fluorescence is shown in percentage relative to the x-mean fluorescence of the AAV2 condition (adjusted to 100\%).

Figure 5: Effect of $7 \mathrm{m8}$ insertion on retinal transduction efficiency of AAV2-, AAV5-, AAV8- and AAV9-CAG-GFP vectors. In vivo eye fundus imaging showing GFP fluorescence 6 weeks after intravitreal injection with the different AAV vectors. Note that the only variants that benefit from $7 \mathrm{~m} 8$ insertion are AAV2 and AAV9. All images were acquired using the same acquisition parameters.

Figure 6: Analysis transduction patterns by AAV9 and AAV9-7m8 vectors encoding GFP under the rhodopsin promoter. (Top) Representative eye fundus images acquired at equal settings showing GFP fluorescence 6 weeks after intravitreal injection (Bottom) Transverse sections of representative retinas treated with the same vectors. Endogenous GFP (green), DAPI (blue), Recoverin (red).

Figure 7: Expression patterns resulting from intrastriatal injections of AAV2, 9, and their $7 \mathbf{m 8}$ insertion variants. (A) Sagittal brain sections showing extent and intensity of GFP 
expression across a representative brain section (at equal settings). (B) Transduction volumes in $\mu \mathrm{m}^{3}$ based on transduced surface areas across one series of sections multiplied by total thickness of the sections ( $\mathrm{n}=5$ mouse brains for each vector) (left). Mean transduction intensity expressed as mean gray value across the section for each vector measured in Image J in series of sections of 5 mouse brains (right). Error bars represent SEM between different mice.

Figure 8: Retinal barriers to AAV transduction. Illustration representing the three main physical barriers to retinal transduction by AAVs injected into the vitreous. The vectors first diffuse in the vitreous and reach the first barrier -the inner limiting membrane (ILM), which is composed of a dense network of polysaccharides secreted via Müller glial cell endfeet. The second barrier is the extracellular matrix of retinal cells which impedes diffusion and cell entry. Lastly AAV particles are faced with the third barrier for entry inside the nucleus: the cell and nuclear membrane.

\section{Supplemental Information}

Table S1: AAV vectors used in this study. Genomic titers of AAV-CAG-GFP vector stocks were determined by quantitative real-time PCR. AAV2-Ala and AAV2-7m8-Ala (R475A, R484A, K532A); AAV5-Ala and AAV5-7m8.Ala (M569, Y585A, L587A); AAV9-Ala and AAV9-7m8.Ala (D271A, N272A).

Figure S1: In vitro transduction efficiency of AAV2, 5, 9 and their mutated versions analyzed by flow cytometry. MOI was adjusted to obtain $40 \%$ of GFP+ cells for each vector on their respective permissive cell lines. GFP fluorescence is shown in percentage relative to the $\mathrm{x}$ - 
mean fluorescence of the parental serotype (AAV2, AAV5 or AAV9). (A) Transduction efficiency of AAV2 and its mutants on HEK-293T cell line. (B) Transduction efficiency of AAV5 and its mutants on $661 \mathrm{~W}$ cell line. The AAV5-7m8. Ala mutant was analyzed at a lower MOI due low titer of the virus (see Table S1). The MOI used gave $20 \%$ of infected cells by the control virus (AAV5). (C) Transduction efficiency of AAV9 and its mutants on CHO-Lec2 cell line. $\mathrm{n}=3$ technical replicates for each condition.

Figure S2: Receptor binding properties of AAV9 and AAV9-7m8. Transduction efficiency of AAV9 and AAV9-7m8 on CHO-Lec2 cells in competition with galactose binding molecule (Lectin PNA) was analyzed by flow cytometry. Multiplicity of infection (MOI) was adjusted for each virus so at least $40 \%$ of cells were infected in the control condition (AAV9: MOI 550 000; AAV9-7m8: MOI 75 000). GFP expression is shown in percentage relative to the control condition ( $0 \mu \mathrm{g}$ PNA) represented as $100 \%$.

Figure S3: Effect of $7 \mathrm{m8}$ insertion on the retinal tropism of AAV5-, AAV8- and AAV9CAG-GFP vectors after intravitreal injections. Histological cross-sections showing GFP expression patterns by the new $7 \mathrm{~m} 8$ variants and their parental serotypes.

\section{Figure S4: Retinal transduction efficiency of AAV2, 5, 8, 9 and their peptide insertion} variants after subretinal injection. GFP expression pattern of each vector visualized on eye fundus images at equal settings and on retinal cross-sections (inset). Optimal confocal acquisition settings have been used for each vector. GFP: green, DAPI: blue. 
Movie S1: 3D reconstruction of a HEK cell infected with AAV2. AAV2 particles marked with A20 antibody are represented in magenta when they are in the nuclear compartment; in green when they are localized to the cytosol. Cell membrane and cytoskeleton marked with phalloidin are shown in white and nucleus is shown in blue. Scale bar is indicated in the left bottom corner.

\begin{abstract}
Movie S2: 3D reconstruction of a HEK cell infected with AAV2-7m8. AAV2-7m8 particles marked with A20 antibody are represented in magenta when they are in the nuclear compartment; in green when they are localized to the cytosol. Cell membrane and cytoskeleton marked with phalloidin are shown in white and nucleus is shown in blue. Scale bar is indicated in the left bottom corner.
\end{abstract}





D
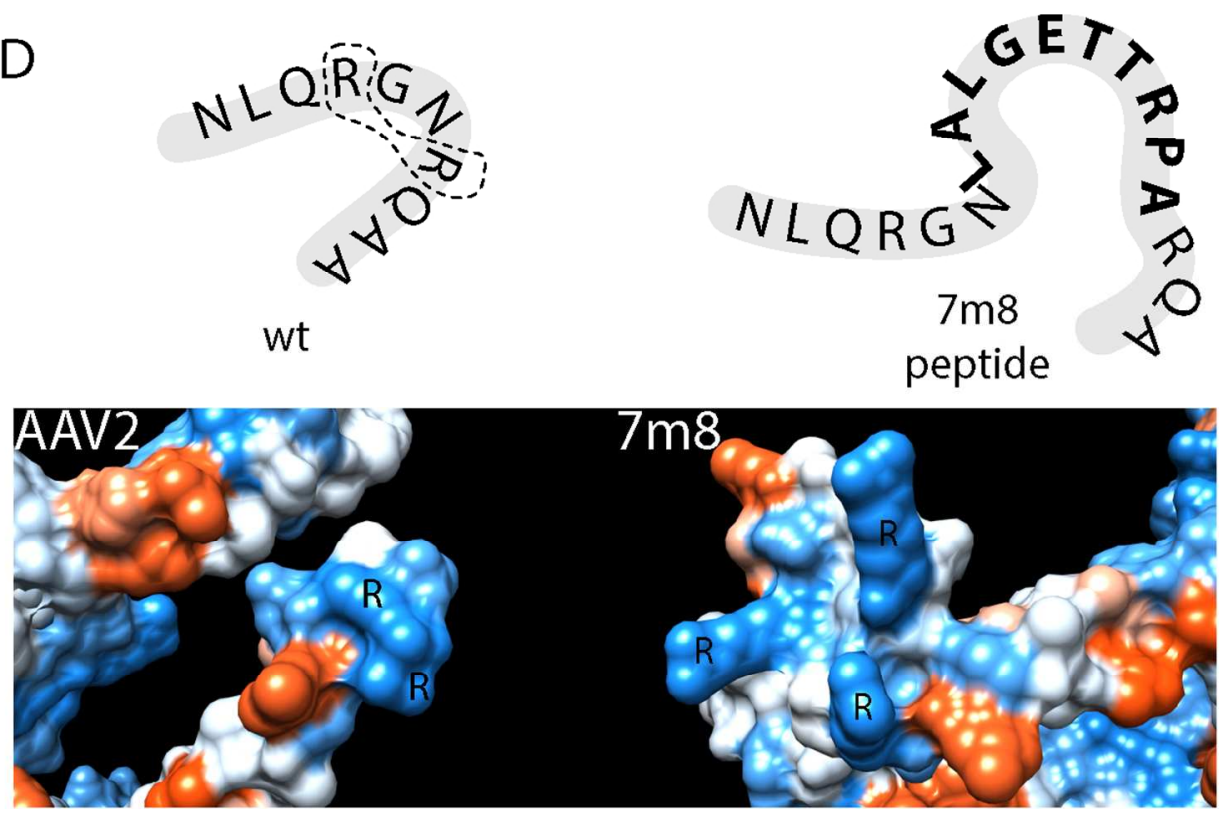

Fig1

$113 \times 127 \mathrm{~mm}(300 \times 300 \mathrm{DPI})$ 
A Design of $7 \mathrm{~m} 8$ inserted AAV vectors

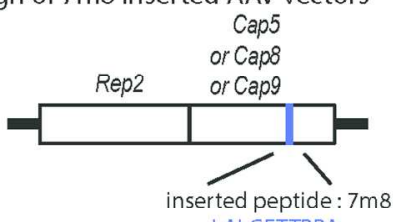

LALGETTRPA

\section{B}

AAV2 $\quad$ RGN587 RQA

AAV2-7m8 RGN LALGETTRPA RQAA

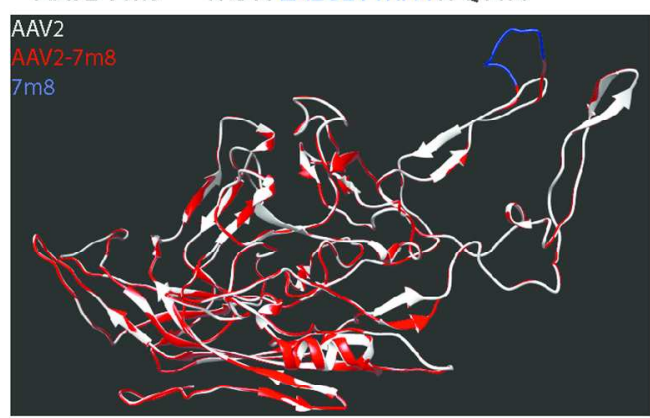

$\mathrm{D}$



C
AAV5 NNL575QGS

AAV5-7m8 NNLLALGETTRPA Q G S

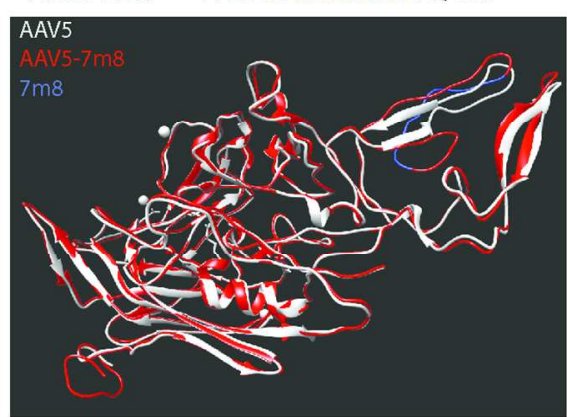

E

AAV8 QQQN590TAP

AAV8-7m8 QQQNLALGETTRPATAP

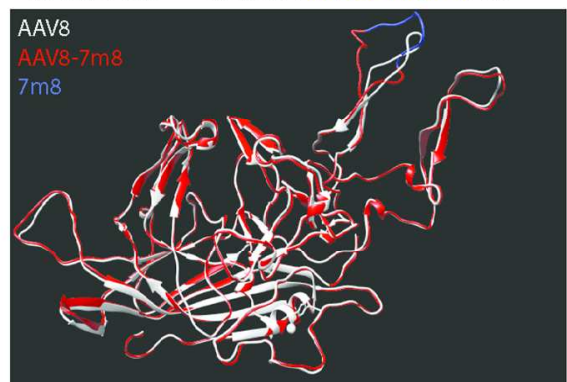

Fig2

$128 \times 129 \mathrm{~mm}(300 \times 300$ DPI $)$ 


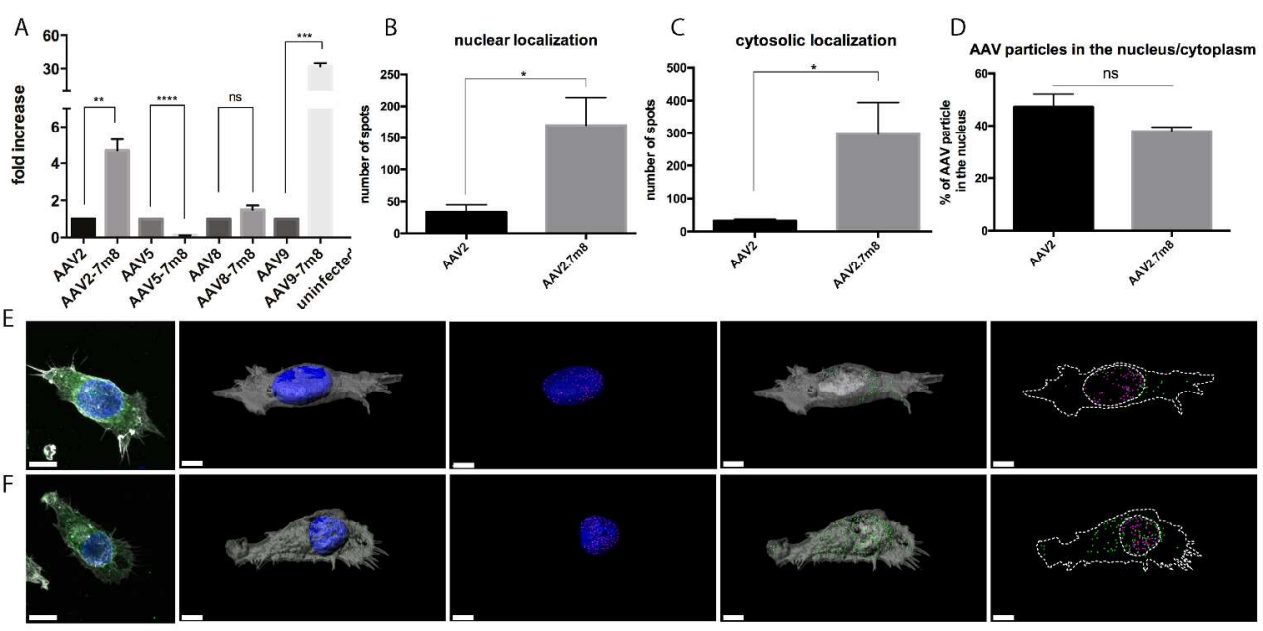

Fig3

$217 \times 108 \mathrm{~mm}(300 \times 300$ DPI $)$ 

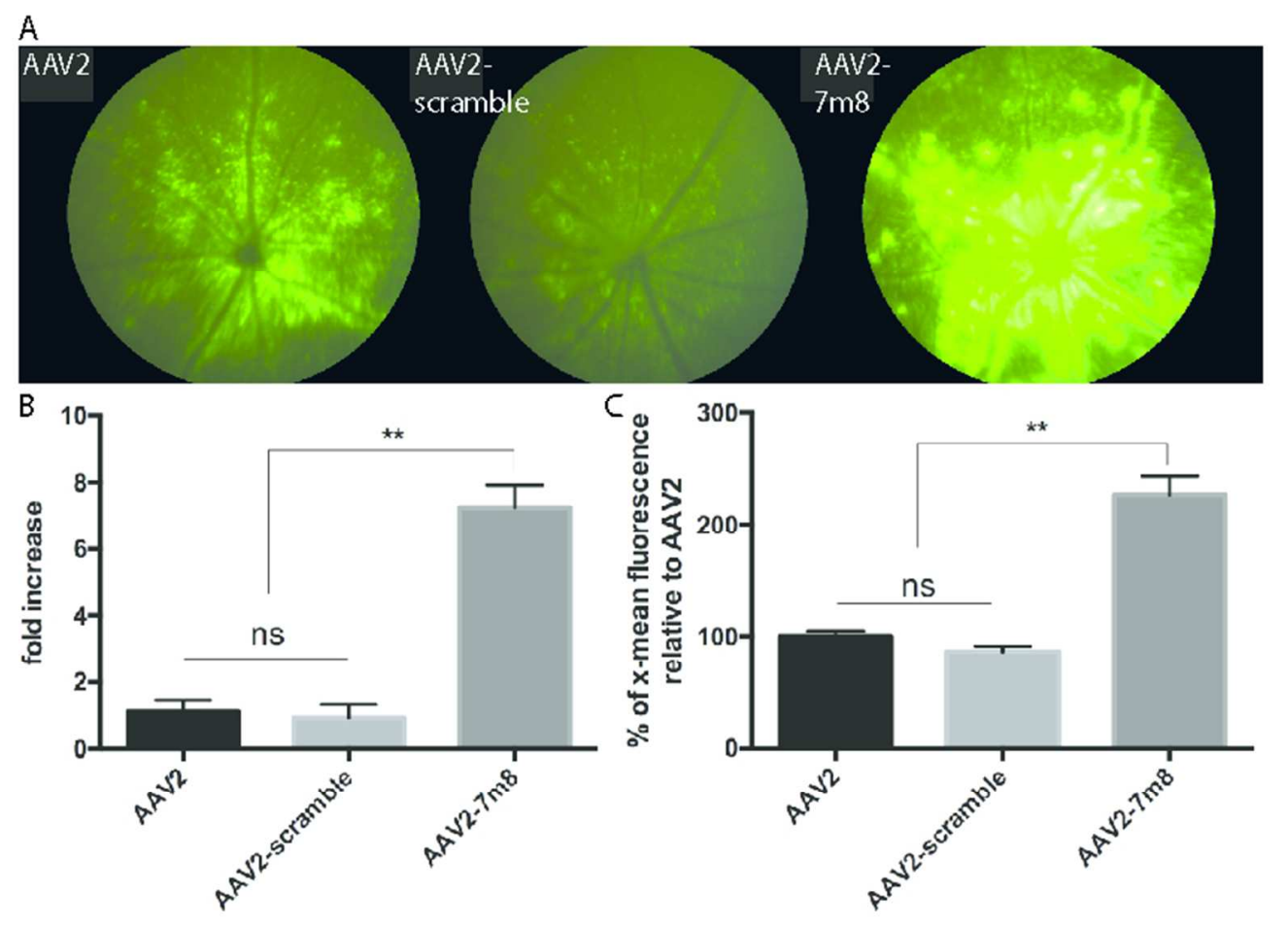

Fig4

$71 \times 51 \mathrm{~mm}(300 \times 300$ DPI $)$ 


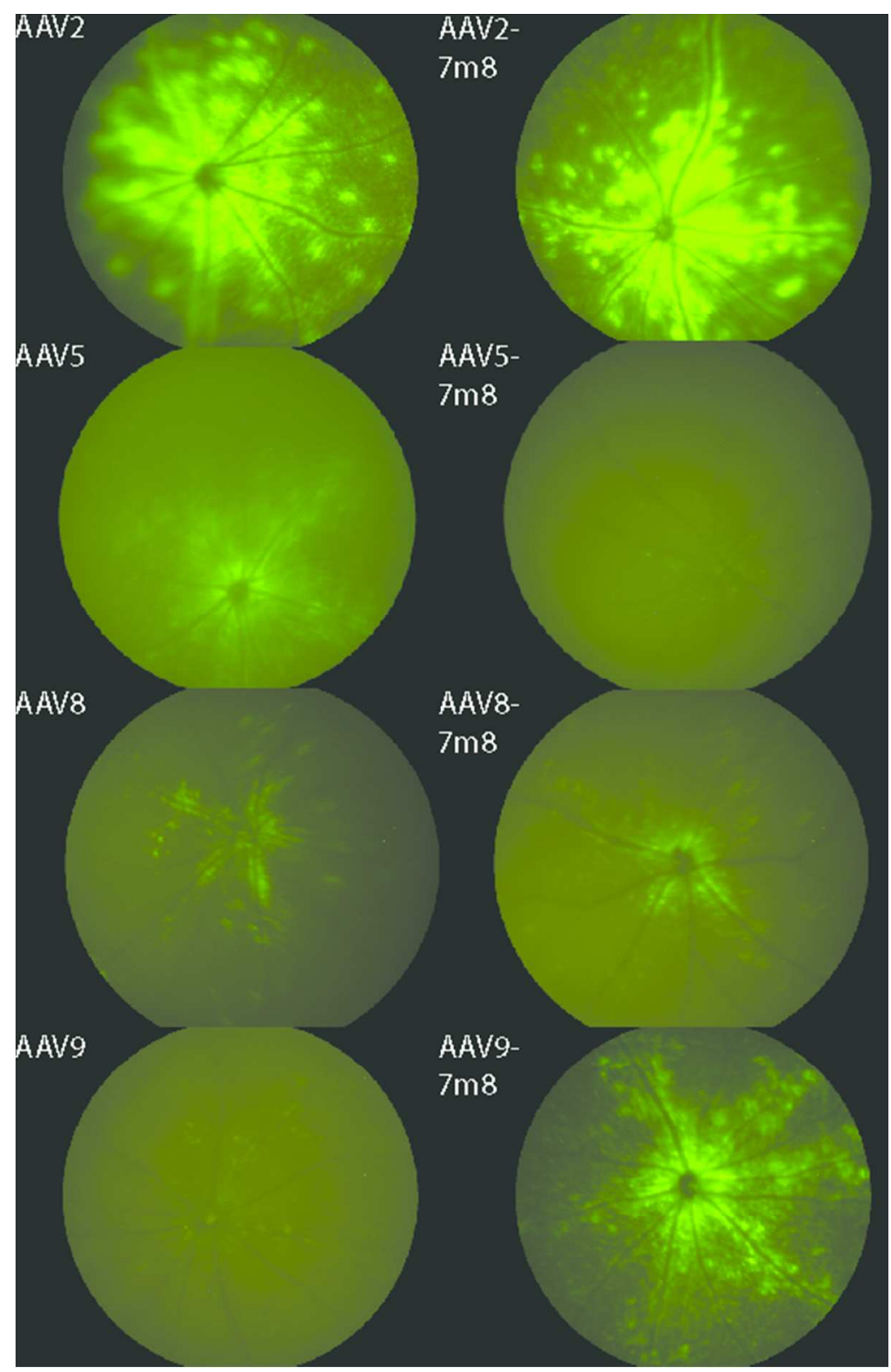

Fig5

$46 \times 71 \mathrm{~mm}(300 \times 300$ DPI $)$ 


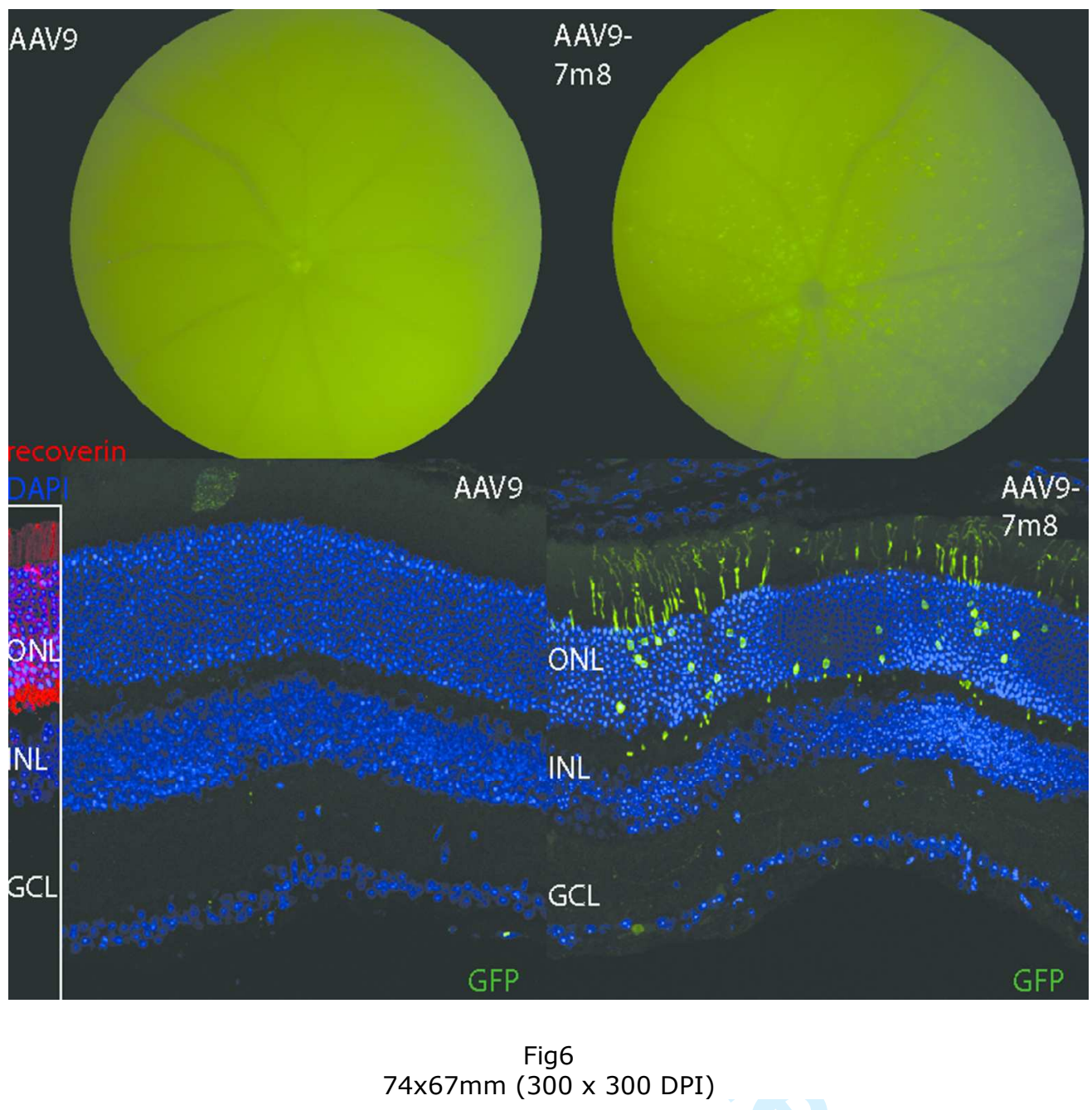



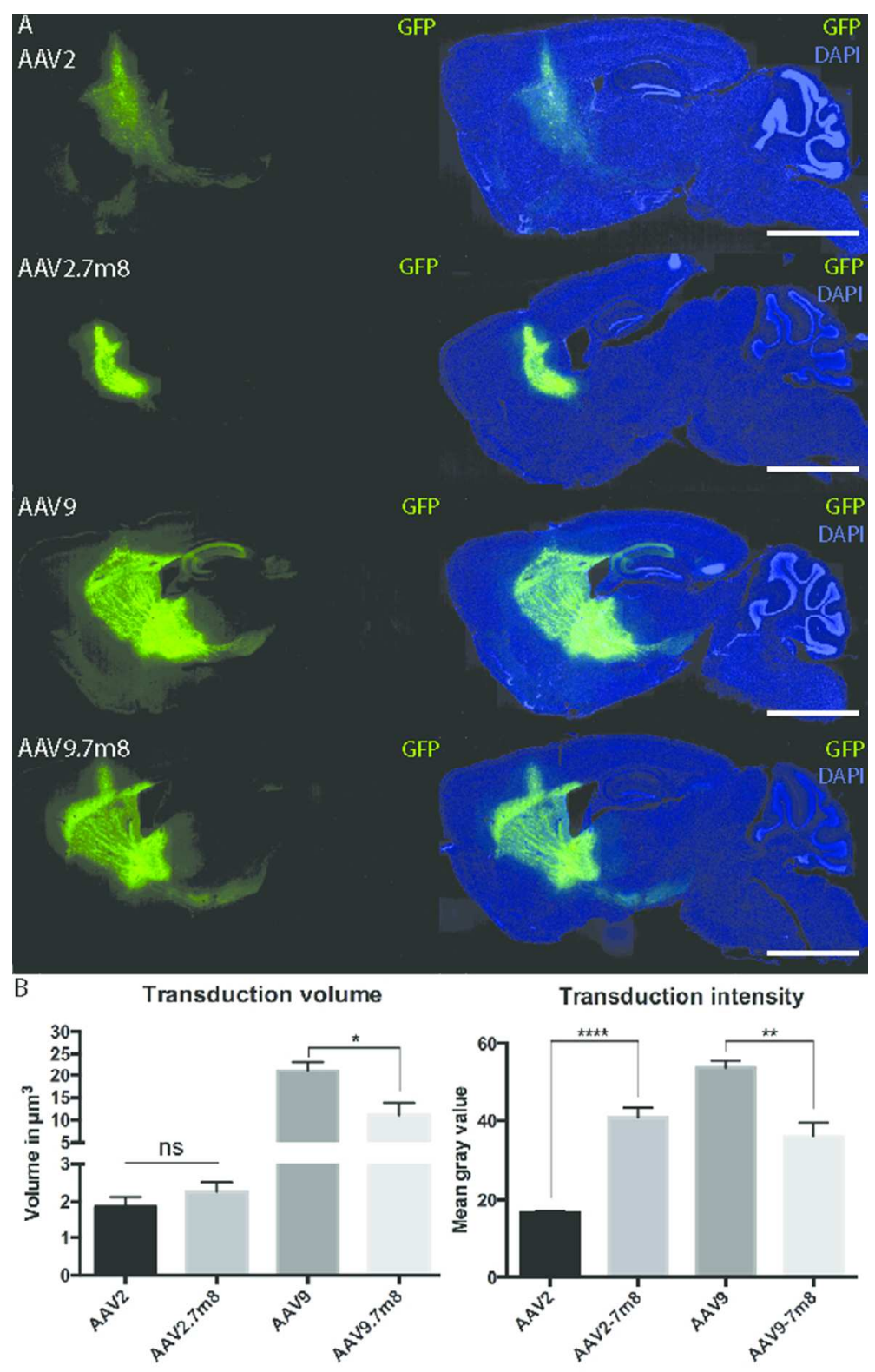

Fig7

$55 \times 87 \mathrm{~mm}(300 \times 300$ DPI $)$ 

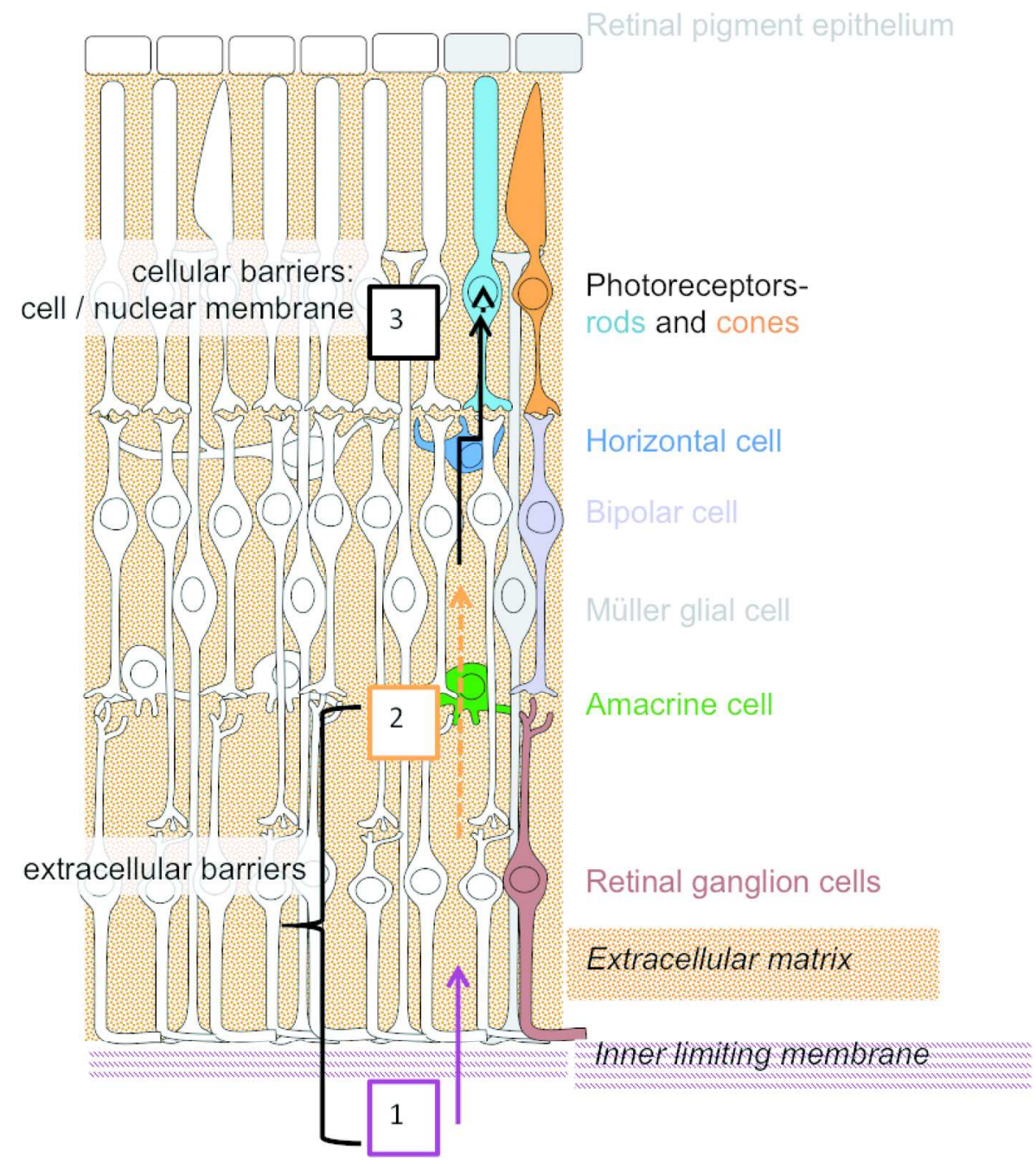

Fig8

$152 \times 156 \mathrm{~mm}(300 \times 300$ DPI $)$ 
Table S1:

\begin{tabular}{|l|l|}
\hline GFP vector & Genomic titers (vector genomes vg/mL) \\
\hline AAV2 & $6 \times 10^{12}$ \\
\hline AAV2-7m8 & $3 \times 10^{12}$ \\
\hline AAV2-scramble (AAKKTIENRA) & $3 \times 10^{12}$ \\
\hline AAV2-Ala & $8 \times 10^{11}$ \\
\hline AAV2-7m8.Ala & $2 \times 10^{11}$ \\
\hline AAV5 & $2 \times 10^{13}$ \\
\hline AAV5-7m8 & $1 \times 10^{14}$ \\
\hline AAV5-Ala & $6.91 \times 10^{12}$ \\
\hline AAV5-7m8.Ala & $4.91 \times 10^{11}$ \\
\hline AAV9 & $2 \times 10^{13}$ \\
\hline AAV9-7m8 & $6 \times 10^{12}$ \\
\hline AAV9-Ala & $2.34 \times 10^{12}$ \\
\hline AAV9-7m8.Ala & $1.42 \times 10^{11}$ \\
\hline AAV8 & $7.5 \times 10^{13}$ \\
\hline AAV8-7m8 & $90^{13}$ \\
\hline & \\
\hline & \\
\hline
\end{tabular}



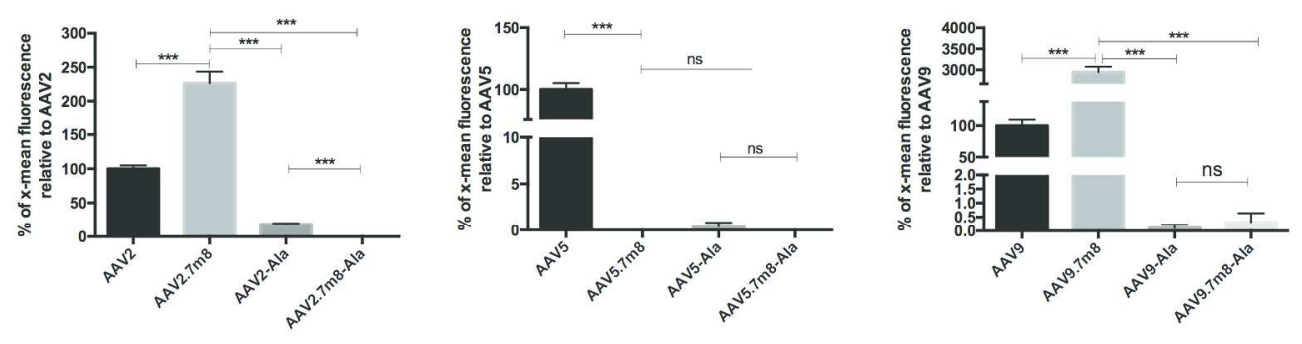

$228 \times 59 m m(300 \times 300$ DPI) 


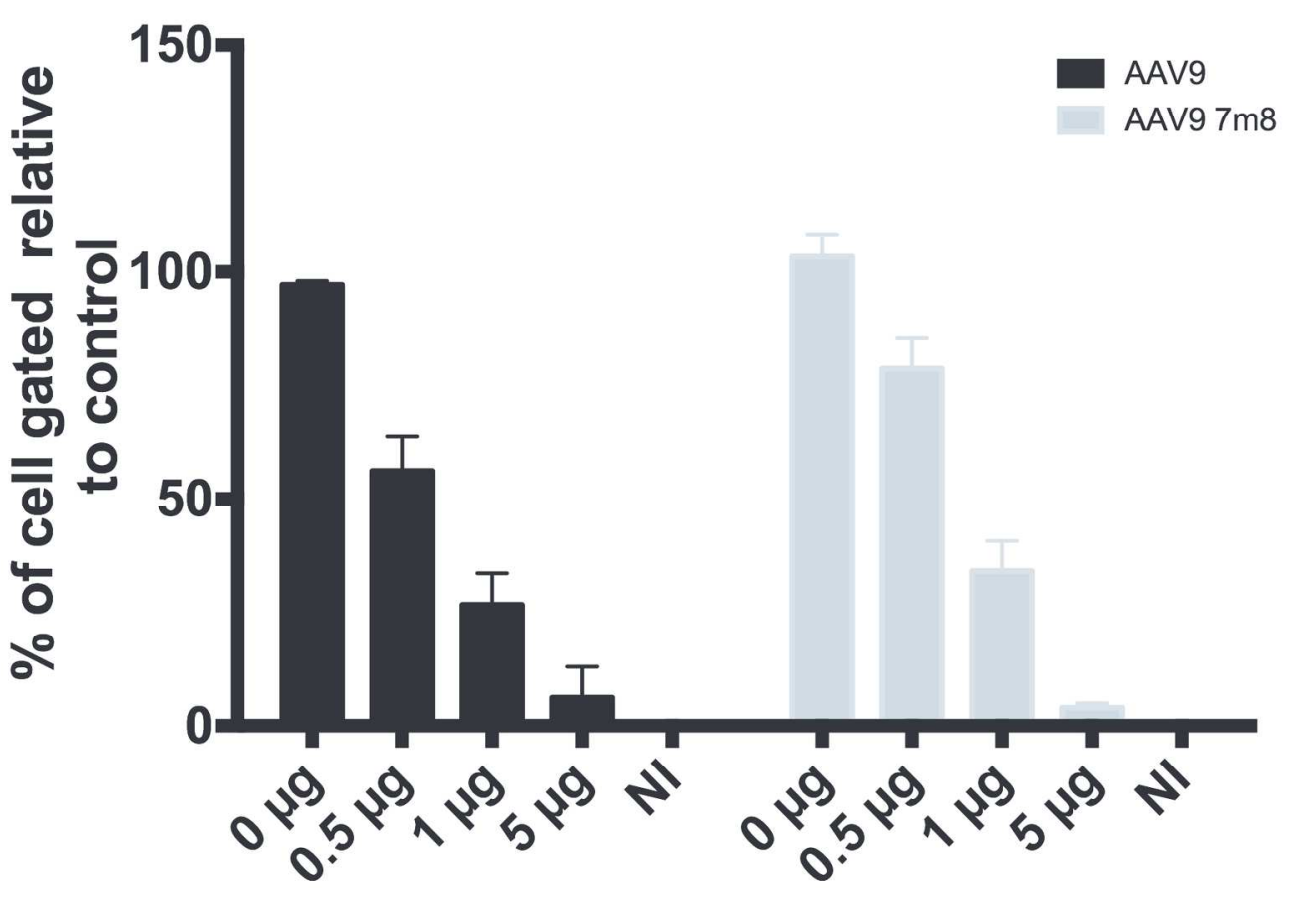

$169 \times 118 \mathrm{~mm}(300 \times 300 \mathrm{DPI})$ 


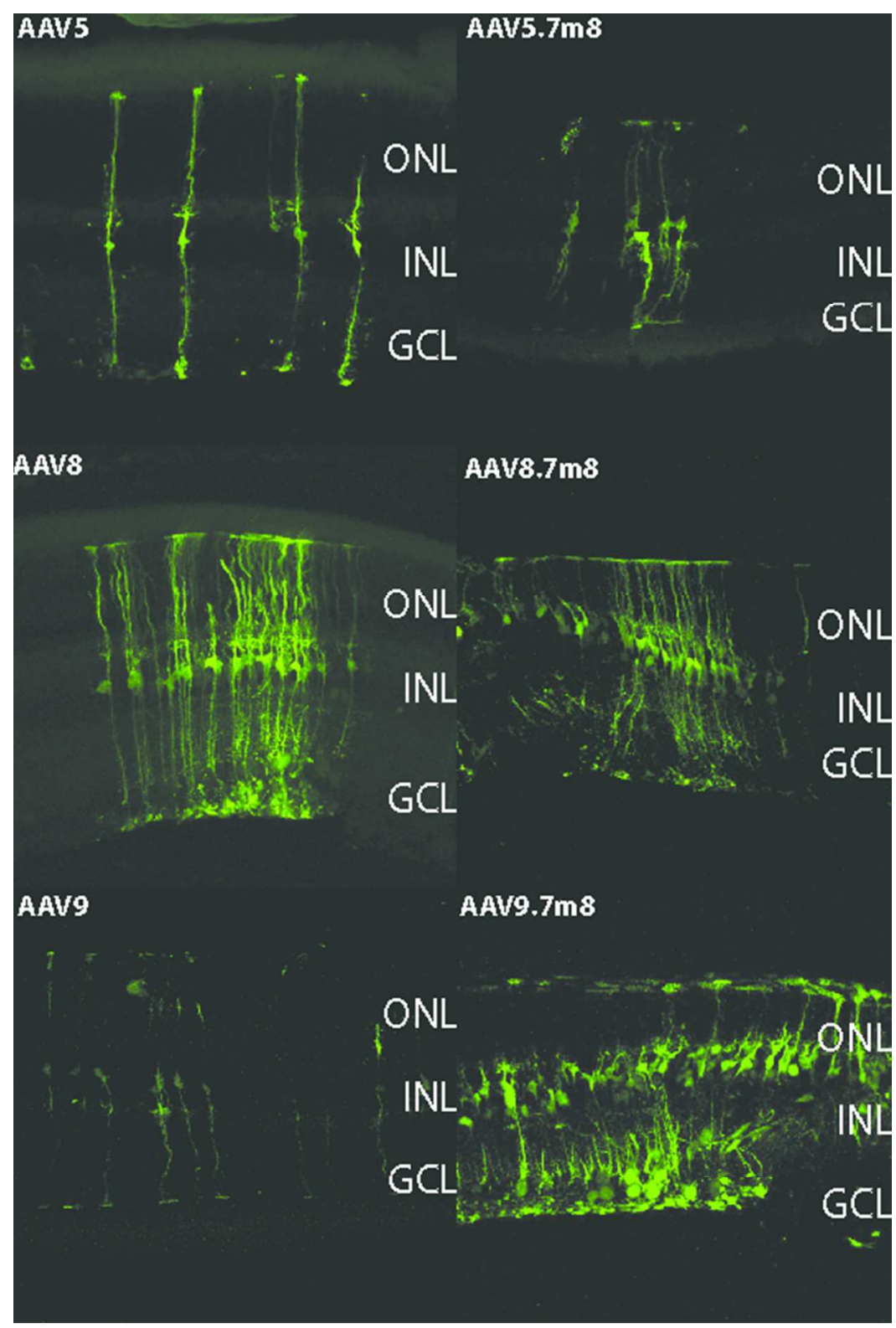

$45 \times 67 \mathrm{~mm}(300 \times 300$ DPI $)$ 


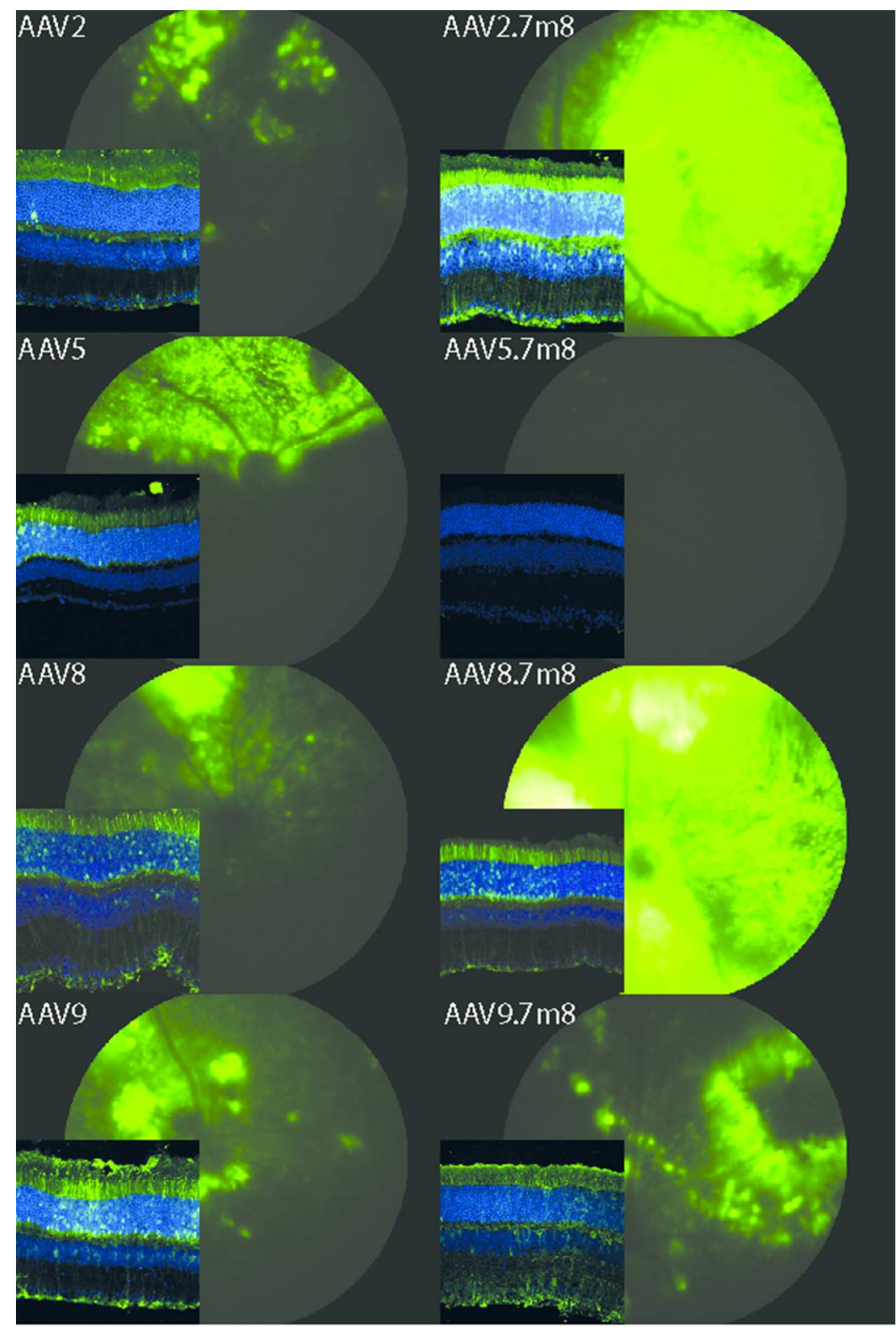

$52 \times 78 \mathrm{~mm}(300 \times 300 \mathrm{DPI})$ 